Short title: psychology of the subject pool

\title{
On the psychology of the psychology subject pool: an exploratory test of the good student effect
}

\author{
Hashem Sadeghiyeh ${ }^{*}, 1$, Siyu Wang ${ }^{1}$, Hannah M. Kyllo${ }^{1}$, Maxwell R. Alberhasky ${ }^{4}$, \\ Shlishaa Savita ${ }^{1}, K_{\text {Kathryn L. Kellohen }}^{1}$, \& Robert C. Wilson ${ }^{1,2,5}$
}

${ }^{1}$ Department of Psychology, University of Arizona

${ }^{2}$ Cognitive Science Program, University of Arizona

${ }^{4} \mathrm{McCombs}$ School of Business, University of Texas at Austin

${ }^{5}$ Evelyn F. McKnight Brain Institute

*Corresponding Author: sadeghiyeh@email.arizona.edu

Department of Psychology, University of Arizona

1503 E University Blvd, Tucson, AZ 85721

This version of the article may not completely replicate the final authoritative version published in Journal of Individual Differences at https://doi.org/10.1027/1614-0001/a000327. It is not the version of record and is therefore not suitable for citation. Please do not copy or cite without the permission of the author(s).

March 17, 2020 


\begin{abstract}
Many psychology researches are performed through "psychology subject pools" which give participants considerable flexibility in when they participate. This "participant degree-of-freedom" has led to concern that the characteristics of subject pool participants may change with time, with the most engaged students signing up at the start of the semester and the least engaged students leaving it all to the end. In this paper we performed an exploratory analysis to look for evidence of this "good student effect". Consistent with previous work, we find support for the good student effect with earlier participants scoring higher on the Big-5 subscales of Achievement-Striving and Cooperation, as well as Grit and Empathic-Concern. In addition, we found a non-linear effect of time-of-semester on Sensation-Seeking, with this measure peaking in the middle of the semester as well as the end. However, the vast majority of the measures we tested, including measures of personality, cognition, decisionmaking and social interaction, did not correlate with time-of- semester or timeof-day at all. Thus, we conclude that, while some studies directly related to measures of Grit and Sensation-Seeking would do well to recruit throughout the semester, in most cases any bias introduced by the good student effect is likely to be small.
\end{abstract}

Keywords - psychology subject pool, time-of-semester, time-of-day, individual differences, grit, sensation seeking 


\section{Introduction}

Unless the research is aimed at a specific population, the subjects of most psychology experiments, especially in the United States, are psychology students, mostly those taking introductory psychology classes (Findley \& Cooper, 1981; Higbee, Millard, \& Folkman, 1982). In almost all of these subject pool systems, students are compensated by receiving course credit. According to Kangas and Hackenberg (2009) the use of course credit as an incentive was first reported by Greene and Sutor (1971) in the Journal of the Experimental Analysis of Behavior. Then after a decade of infrequent use, it became common practice in the mid-1980s and 1990s when around $32 \%$ of undergraduate psychology departments (Landrum \& Chastain, 1999) and $74 \%$ of psychology departments with a graduate program (Sieber \& Saks, 1989) used subject pools.

The most obvious benefit of such a system is convenience and access to lots of subjects at minimal cost (Cassidy \& Kangas, 2014). It also has an educational benefit to the participants. The downside of such a system is that it may introduce several biases to the sample. First, college undergraduates represent only a tiny sliver of the total population differing along dimensions such as age, race/ethnicity, and social-economic status (SES) (Cooper, Baumgardner, \& Strathman, 1991). Second is that subjects have considerable choice in the experimental process. For example, Jackson, Procidano, and Cohen (1989) showed that subjects may choose specific types of experiments based on their personality traits.

Here we focus on a specific kind of subject choice, namely the choice of date and time of participation. Across all psychology studies, Miller (1981) estimated in $81 \%$ of cases, subjects have freedom to choose the date and time of experiment. In a subject pool situation, this number is likely closer to $100 \%$. Regardless of the actual number, a subject's 
freedom to choose may introduce bias as certain personality types may be more likely to participate early or late. This bias could be especially problematic if the experiment is running for just a brief period concentrated either early or late in the semester (Cooper et al., 1991).

Anecdotally, we find that most of our colleagues (if they have the option between early and late subjects) prefer early subjects due to a belief that the quality of data is higher in early than late participants. The literature is in line with this implicit impression, which Zelenski, Rusting, and Larsen (2003) call the "good student effect". For example, early participants have higher GPAs (Cooper et al., 1991), more positive attitudes toward the experiment (Adair, 1973), more internal control beliefs and interest in academia (Evans \& Donnerstein, 1974), and are more motivated and better organized (Jackson et al., 1989) than late participants who tend to be more playful, more exhibitionistic, less socially responsible, and less dominant (Holden \& Reddon, 1987). Interestingly procrastination does not seem to be correlated with time-of-semester (Wang \& Jentsch, 1998). Aviv, Zelenski, Rallo, and Larsen (2002) investigated the relations between time-of-semester and the Big Five personality traits (NEO PI-R; McCrae \& Costa, 1997) and found weak but significant correlations between early participation and higher Conscientiousness, lower Extraversion and lower Openness to Experience. In addition to personality factors, demographic factors have also been found to vary across the semester. Most notably is the observation that females tend to participate earlier than males (Aviv et al., 2002; Ebersole et al., 2016).

Another related question concerns the possible relationship between the time of participation in the day (time-of-day) and the results of the study. There are fewer studies on the relationship between time-of-day and personality traits and it seems the relationships are fewer and weaker compared to the time-of-semester factor. For example, 
Zelenski et al. (2003) found significant positive correlations be-tween participation later in the day and social desirability, need for achievement, extraversion, conscientiousness, activity level, and negative correlation with birth order. Zelenski et al. (2003) also reported an indirect correlation between time-of-semester and time-of-day through a self-report "morningness" questionnaire: participants higher in morningness tend to sign up earlier in the semester.

Several authors have proposed a solution whereby subjects are recruited over the entire course of semester instead of running an experiment in a short period of semester or the day (Cooper et al., 1991; Zelenski et al., 2003). However, such a conservative solution could be demanding, and it is often more convenient to run experiments all at once over a period of one or two weeks. Given the widespread usage of short-period sampling, the question is does it meaningfully bias the results? While some authors highlight the importance of its consideration (e.g. Evans \& Donnerstein, 1974; Richter, Wilson, Milner,\& Senter, 1981), others concluded the effect sizes were small and inconsistent and suggested researchers should not be worried about the time-of-semester effect (Cooper et al., 1991; Wang \& Jentsch, 1998). More recently, Ebersole et al. (2016) investigated the time-of-semester variation in 2696 participants in 20 different subject pools and with 10 experimental or correlational effects (e.g. Stroop task, availability heuristic, metaphoric structuring) and reported very small or no differences in those effects between early and late participants.

In the current study we investigated the relationships between time-of-semester and time-of-day factors with a variety of demographic and personality traits we have used in our previous studies (Sadeghiyeh, Wang \& Wilson, 2018; Sadeghiyeh, 2019; Sadeghiyeh et al., 2020). In these studies, demographic and personality traits were not the main focus of the study but acquired as potential covariates and for exploratory analyses and included 
measures of demographic and different personality, cognitive, decision-making and social traits. Based on the previous literature we predicted weak to moderate correlations between time-of-semester and a variety of traits like gender, GPA, Extraversion, Agreeableness, Conscientiousness, Grit, and Sensation-seeking. Although because the experiments were not designed with this question in mind all analyses are corrected for multiple comparisons.

\section{Methods}

\section{Participants}

We collected data from a total of 485 participants (ages 18-29, average $=19.08$; Females $=$ 279 , Males $=205$, Transgender $=1)$ who took part in various experiments in our lab in 2015 and 2016 in which they responded to a bundle of questionnaires using Qualtrics. Not all of the measures were used in each experiment, so we have different sample numbers (from 146-485) for different measured traits. Participants were recruited through the Psychology subject pool at the University of Arizona and received course credit for their participation. The experiments were advertised online through SONA system and usually provided participants with a wide range of choices regarding the date (from early to last days of semester; both weekdays and weekends) and time (from 7 am to $7 \mathrm{pm}$ ). All experiments were run in person on a computer in an experimental room with up to 3 other participants. Before answering the questionnaires, participants played a specific computer task depending on the purpose of the experiment. The task usually took about 20-30 minutes and the whole experiment was designed either for a 1-hour or 2-hour slot. All participants gave informed consent and the study was approved by the Institutional Review Board at the University of Arizona. 


\section{Measures}

To aid exposition, we group the questionnaires used in our experiments in six categories based on the types of individual differences measured:

1. Demographic: gender, age, race, US-born, years-in-US, GPA, parents' job, parents' education, family income, family size, and subjective SES.

2. Personality-Big Five: IPIP-NEO-120 (Johnson, 2014).

3. Personality-Others: Grit Scale (Duckworth, Peterson, Matthews, \& Kelly, 2007), Dispositional Positive Emotion Scale (DPES) (Shiota, Keltner, \& John, 2006), Personal Need for Structure (Neuberg \& Newsom, 1993), Life History Strategy (Mini-K) (Figueredo et al., 2006), and Life Orientation Test-Revised (LOT-R) (Scheier, Carver, \& Bridges, 1994).

4. Cognitive: Rotter's Locus of Control (Rotter, 1966), Need for Cognition (Cacioppo \& Petty, 1982), and Santa Barbara Sense of Direction (Hegarty, Montello, Richardson, Ishikawa, \& Lovelace, 2006).

5. Decision-making: Arnett Inventory of Sensation Seeking (AISS) (Arnett, 1994), Financial Risk Tolerance Assessment (Grable \& Lytton, 1999), Barratt Impulsivity Scale (BIS-11) (Patton, Stanford, \& Barratt, 1995), Tolerance of Ambiguity (Stanley Budner, 1962), Interest/Deprivation Epistemic Curiosity Scale (I/D) (Litman, 2008), and Curiosity and Exploration Inventory (CEI-II) (Kashdan et al., 2009).

6. Social: Interpersonal Reactivity Scale (IRI) (Davis, 1983), Revised Competitiveness (Harris \&Houston, 2010), Fear of Negative Evaluation (Leary, 1983), Social and Economic Conservatism Scale (SECS) (Everett, 2013), and Collectivism/Individualism (Triandis \& Gelfand, 1998). 
For a more detailed description of the measures please see Supplementary Materials A.

\section{Results}

Table 1 summarizes the descriptive statistics (minimum, maximum, mean, standard deviation, and number of participants) for most of the personality and demographic traits in our study (categorical and ordinal parameters are excluded). To have a better sense of the distribution of traits in our sample, the histogram of all 105 demographic and personality traits can be found in Supplementary Materials B Figures S1-S5.

We defined the time-of-semester by counting days from the opening of subject pool (when students could sign up for experiments). At the University $\mathrm{f}$ Arizona, the first day of experiments was 7 and 10 days after the first day of semester in Fall and Spring semesters, respectively. The range of days of experiment happened to be exactly 100 days for each semester. The median of time-of-semester in our 485 participants was 66 (Males $=67$; Females $=64)$ which shows most subjects signed up for the second half of the semester. Landrum and Chastain (1995) also reported most of their subjects participated in the second half of semester. The average "days into semester" was 70.1 which seems very close to ours considering an approximately one-week difference in our way of counting the time-ofsemester and theirs.

Time-of-day was defined as the linear transformation of the time of experiment into 0-1 interval. For example, $12 \mathrm{am} \rightarrow 0.0,12 \mathrm{pm} \rightarrow 0.5,11: 59 \mathrm{pm} \rightarrow$ 1.0. The average of time-ofday for our 485participants was $0.584(\sim 2: 01 \mathrm{pm})$ (Males $=0.60 \sim 2: 24 \mathrm{pm}$; Females $=$ $0.57 \sim 1: 41 \mathrm{pm})$.

There was a significant correlation between time-of-semester and time-of-day of 
participation, (Pearson's $\mathrm{r}(483)=.10 ; \mathrm{p}=0.03)$, which shows those who tend to participate earlier in the semester also tend to participated earlier in the day. This finding is in line with Zelenski et al. (2003) who found that people high in "morningness" tend to participate early in the semester, though their "morningness" trait was assessed by a self-report questionnaire while in ours it is the actual time subjects participated in the study. 
Table 1: Descriptive Statistics; Range, Mean, \& Standard Deviation

\begin{tabular}{|c|c|c|c|c|c|}
\hline trait & Min & Max & Mean & SD & $\mathrm{N}$ \\
\hline Age & 18 & 29 & 19.08 & 1.38 & 485 \\
\hline Years In US & 0 & 29 & 15.79 & 6.50 & 485 \\
\hline GPA High & 2 & 4.7 & 3.50 & 0.41 & 483 \\
\hline Temporal Discounting & 4 & 27 & 15.26 & 4.15 & 220 \\
\hline Family Size & 1 & 15 & 4.09 & 1.39 & 485 \\
\hline SES & 0.4 & 3 & 2.16 & 0.53 & 485 \\
\hline Subj SES & 10 & 100 & 63.53 & 18.52 & 485 \\
\hline N1 Anxiety & 4 & 20 & 12.98 & 3.62 & 220 \\
\hline N2 Anger & 4 & 20 & 11.23 & 3.78 & 220 \\
\hline N3 Depression & 4 & 20 & 9.75 & 3.72 & 220 \\
\hline N4 Self Consciousness & 4 & 20 & 11.50 & 3.14 & 220 \\
\hline N5 Immoderation & 4 & 20 & 12.01 & 2.96 & 220 \\
\hline N6: Vulnerability & 4 & 20 & 10.91 & 3.56 & 220 \\
\hline Neuroticsim & 33 & 106 & 68.37 & 14.81 & 220 \\
\hline E1 Friendliness & 4 & 20 & 14.55 & 3.07 & 220 \\
\hline E2 Gregariousness & 4 & 20 & 13.24 & 3.57 & 220 \\
\hline E3 Assertiveness & 4 & 20 & 14.25 & 3.07 & 220 \\
\hline E4 Activity Level & 5 & 20 & 12.28 & 2.80 & 220 \\
\hline E5 Excitement Seeking & 4 & 20 & 14.26 & 3.09 & 220 \\
\hline E6 Cheerfulness & 7 & 20 & 15.68 & 2.78 & 220 \\
\hline Extraversion & 31 & 112 & 84.27 & 12.54 & 220 \\
\hline O1 Imagination & 7 & 20 & 14.80 & 2.98 & 220 \\
\hline $\mathrm{O} 2$ Artistic Interests & 6 & 20 & 14.02 & 3.30 & 220 \\
\hline O3 Emotionality & 5 & 20 & 14.52 & 3.25 & 220 \\
\hline O4 Adventurousness & 4 & 19 & 11.79 & 2.81 & 220 \\
\hline O5 Intellect & 6 & 20 & 13.24 & 3.09 & 220 \\
\hline O6 Liberalism & 4 & 19 & 11.72 & 2.91 & 220 \\
\hline Openness & 52 & 109 & 80.09 & 11.03 & 220 \\
\hline A1 Trust & 4 & 20 & 13.83 & 3.23 & 220 \\
\hline A2 Morality & 8 & 20 & 15.72 & 3.12 & 220 \\
\hline A3 Altruism & 6 & 20 & 16.06 & 2.57 & 220 \\
\hline A4 Cooperation & 4 & 20 & 15.13 & 3.17 & 220 \\
\hline A5 Modesty & 4 & 20 & 12.79 & 3.41 & 220 \\
\hline A6 Sympathy & 8 & 20 & 14.92 & 2.50 & 220 \\
\hline Agreeableness & 60 & 113 & 88.46 & 11.38 & 220 \\
\hline C1 Self Efficacy & 4 & 20 & 14.89 & 2.64 & 220 \\
\hline C2 Orderliness & 4 & 20 & 13.09 & 3.67 & 220 \\
\hline C3 Dutifulness & 7 & 20 & 15.44 & 2.40 & 220 \\
\hline C4 Achievement Striving & 4 & 20 & 14.41 & 3.06 & 220 \\
\hline C5 Self Discipline & 4 & 20 & 12.89 & 2.76 & 220 \\
\hline C6 Cautiousness & 4 & 20 & 12.77 & 3.53 & 220 \\
\hline Conscientiousness & 44 & 117 & 83.49 & 12.86 & 220 \\
\hline BIS Attentional-Attention & 5 & 19 & 10.95 & 2.53 & 393 \\
\hline BIS Attentional-Cognitive Instability & 3 & 12 & 6.75 & 1.79 & 393 \\
\hline BIS Attention & 9 & 29 & 17.70 & 3.51 & 393 \\
\hline BIS Motor-Motor & 8 & 28 & 15.61 & 3.54 & 393 \\
\hline BIS Motor-Perseverance & 4 & 14 & 7.20 & 1.85 & 393 \\
\hline
\end{tabular}


Table 1- Continue: Range, Mean, \& Standard Deviation

\begin{tabular}{|c|c|c|c|c|c|}
\hline trait & Min & Max & Mean & SD & $\mathrm{N}$ \\
\hline BIS Motor & 12 & 41 & 22.80 & 4.53 & 393 \\
\hline BIS Nonplanning-Self Control & 6 & 24 & 12.94 & 3.06 & 393 \\
\hline BIS Nonplanning-Cognitive Complexity & 5 & 18 & 12.07 & 2.49 & 393 \\
\hline BIS Nonplaning & 11 & 41 & 25.02 & 4.69 & 393 \\
\hline BIS Total & 39 & 92 & 65.52 & 9.99 & 393 \\
\hline Tolerance Of Ambiguity Novelty & 7 & 28 & 16.97 & 3.41 & 391 \\
\hline Tolerance Of Ambiguity Complexity & 15 & 53 & 32.00 & 5.25 & 391 \\
\hline Tolerance Of Ambiguity Insolubility & 3 & 19 & 11.80 & 2.53 & 391 \\
\hline Tolerance Of Ambiguity Total & 37 & 87 & 60.76 & 7.23 & 391 \\
\hline Personal Need For Structure & 25 & 62 & 40.94 & 6.66 & 219 \\
\hline I/D Interest-Type & 6 & 20 & 14.14 & 2.83 & 219 \\
\hline I/D Deprivation-Type & 5 & 20 & 11.35 & 2.92 & 219 \\
\hline I/D Total & 11 & 40 & 25.48 & 4.98 & 219 \\
\hline CEI-II Stretching & 5 & 25 & 16.65 & 3.72 & 219 \\
\hline CEI-II Embracing & 5 & 25 & 15.27 & 4.01 & 219 \\
\hline CEI-II Total & 10 & 50 & 31.92 & 6.98 & 219 \\
\hline DPE Joy & 11 & 42 & 29.35 & 5.42 & 219 \\
\hline DPE Contentment & 6 & 35 & 23.42 & 5.76 & 219 \\
\hline DPE Pride & 5 & 35 & 25.60 & 5.39 & 219 \\
\hline DPE Love & 9 & 42 & 28.20 & 6.27 & 219 \\
\hline DPE Compassion & 9 & 35 & 28.26 & 5.06 & 219 \\
\hline DPE Amusement & 13 & 35 & 26.70 & 4.99 & 219 \\
\hline DPE Awe & 6 & 42 & 29.65 & 6.00 & 219 \\
\hline Sensation Seeking Novelty & 14 & 36 & 25.07 & 4.38 & 391 \\
\hline Sensation Seeking Intensity & 12 & 38 & 24.95 & 4.46 & 391 \\
\hline Sensation Seeking Total & 28 & 69 & 50.02 & 7.51 & 391 \\
\hline Locus Of Control & 2 & 21 & 11.85 & 3.64 & 219 \\
\hline Need For Cognition & 25 & 86 & 56.99 & 10.02 & 481 \\
\hline Mini-K & 34 & 135 & 102.17 & 13.76 & 481 \\
\hline Competitiveness Enjoyment Of Competition & 9 & 45 & 32.30 & 7.56 & 481 \\
\hline Competitiveness Contentiousness & 5 & 25 & 14.39 & 4.06 & 481 \\
\hline Competitiveness Total & 16 & 70 & 46.69 & 9.77 & 481 \\
\hline Sense Of Direction & 25 & 100 & 62.64 & 14.85 & 389 \\
\hline IRI Perspective-Taking & 11 & 35 & 23.92 & 4.56 & 481 \\
\hline IRI Fantasy & 10 & 35 & 23.51 & 5.09 & 481 \\
\hline IRI Empathic Concern & 7 & 35 & 25.84 & 4.80 & 481 \\
\hline IRI Personal Distress & 7 & 31 & 18.36 & 4.48 & 481 \\
\hline Fear Of Negative Evaluation & 12 & 60 & 38.15 & 9.71 & 342 \\
\hline LOT-R & 7 & 30 & 20.19 & 3.64 & 342 \\
\hline Economic Conservatism & -16 & 379 & 178.40 & 71.29 & 341 \\
\hline Social Conservatism & -20 & 600 & 338.51 & 125.54 & 341 \\
\hline Conservatism Total & 56 & 917 & 516.91 & 160.87 & 341 \\
\hline Financial Risk Tolerance & 24 & 56 & 39.78 & 5.76 & 249 \\
\hline Grit Scale & 20 & 57 & 38.55 & 6.50 & 342 \\
\hline Horizontal Individualism & 12 & 36 & 27.93 & 5.52 & 337 \\
\hline
\end{tabular}


Vertical Individualism

$\begin{array}{llll}4 & 36 & 22.24 & 6.62\end{array}$

337

Horizontal Collectivism

$\begin{array}{llll}4 & 36 & 27.15 & 5.44\end{array}$

337

Vertical Collectivism

\begin{tabular}{lllll}
4 & 36 & 27.39 & 5.70 & 337 \\
\hline
\end{tabular}

\section{Correlations with Demographic/Personality traits}

Tables 2-7 summarize the Pearson correlation coefficients between each demographic/personality trait (in six categories) we used in our experiments and both time-of-semester and time-of-day variables. Significant correlations are shown in bold and marked with one star $\left(^{*}\right)$ for $\mathrm{p}<0.05$ and double star $(* *)$ for those still significant after Bonferroni correction for multiple comparisons. We used Holm's sequentially rejective Bonferroni test (Holm, 1979) implemented in MATLAB by Groppe (2020). Table S1 (Supplementary Materials C) shows the calculated adjusted $p$ by this method for the 20 highest $\mathrm{p}$ values in correlations between demographic/personality traits and time-ofsemester. Alternatively, we can implement the Bonferroni correction by setting a protected alpha level of $0.05 / \mathrm{n}$ in which $\mathrm{n}$ is the number of hypotheses. Here we tested correlations between 105 traits with two variables (time-of-semester and time-of-day) yielding 210 tests in total. Applying Bonferroni correction in this way yielded similar results except for A4-Cooperation which survived only the Bonferroni-Holm method.

\section{Demographic}

Table 2 shows the results for the demographic traits. Gender and Age had a negative correlation with time-of-semester (i.e. younger and females participated earlier in the semester than older and males, respectively). This pattern was also observed for the time-of-day: females and younger students participated earlier in the day than males and older students. In line with previous researches, GPA also had a negative correlation with the time-of-semester: 
higher GPA students participated earlier than lower GPA ones. Socio-economic status and family income had a positive correlation with the time-of-semester: higher SES students participated later in the semester than lower SES ones. Lastly, international students tended to participate earlier than US born ones and the more they had lived in the US, the more similar they became to the US-born students in this regard. These correlations are around .10 .15 and none of them stand significant after Bonferroni multiple comparison correction.

\section{Big Five}

For the Big Five traits (Table 3), Openness to Experience (and O6-Liberalism), Agreeableness (and A2-Morality, A4 Cooperation, A6-Sympathy), and Conscientiousness (and C3-Dutifulness, C4-AchievementStriving, C5-Self Discipline) had a negative correlation with time-of-semester, i.e. more Agreeable, more Conscientious and more Open students tend to participate earlier. The only positive correlation was for E2Gregariousness (a sub-scale of Extraversion). This pattern is similar to previous research (Aviv et al., 2002). After Bonferroni correction, only two sub-scales of the Big Five stand significantly correlated with time-of-semester: A4-Cooperation (Pearson's $r(218)=-0.24$; $p<.001$ ) and C4-Achievement Striving (Pearson's r $(218)=-0.25 ; p<.001$ ). None of the main and sub-scales traits was correlated with the time-of-day.

\section{Personality-Other}

Table 4 shows the results for the third category (Personality-Other). Hopefulness as measured by the Life Orientation Test-Revised (LOT-R), the Compassion component of Dispositional Positive Emotion Scale (DPES) and Grit Scale, all showed a negative correlations with the time-of-semester, while no traits in this category showed a significant 
correlation with the time-of-day. Students with higher grit, higher hopefulness, and higher "compassion" (as measured by DPES) tended to participate earlier in the semester. After Bonferroni correction, only Grit scale stands significantly correlated with time-ofsemester (Pearson's r $(340)=-.26 ; \mathrm{p}<.001)$.

\section{Cognitive}

No traits in this group was correlated with time-of-semester or time-of-day, as shown in Table 5 .

\section{Decision-making}

Table 6 summarizes correlations between traits in decision-making group. Arnett Sensation Seeking and both of its subscales: Novelty and Intensity, Barratt Impulsivity Scale (BIS-11) and two of its subscales: Attentional-attention and Nonplanning-Self control, showed a positive correlation with time-of-semester; i.e. the higher the BIS or Sensation seeking, the later students tend to participate. After Bonferroni correction, only Sensation seeking and one of its subscales, Novelty, remained significantly correlated with time-of-semester (Pearson's $\mathrm{r}(389)=.26 ; \mathrm{p}<.001)$. One measure in this category, Tolerance of Ambiguity, showed a significant correlation with time-of-day (Pearson's $\mathrm{r}(389)=.11 ; \mathrm{p}=.03$ ), but it didn't remained significant after Bonferroni correction.

\section{Social}

In the "Social" group, Horizontal Collectivism and all four subscales of Interpersonal Reactivity Scale (IRI) were significantly correlated with time-of-semester (Table 7). IRIPersonal distress showed a positive correlation: the higher the Personal distress, the later the 
participation. Other IRI subscales (Fantasy, Perspective taking, and Empathic concern), as well as Horizontal Collectivism, showed the opposite direction: students with higher empathy/perspective-taking/fantasy/horizontal-collectivism tended to participate earlier in the semester. After Bonferroni correction, only IRI-Empathic Concern remained significantly correlated with time-of-semester (Pearson's r $(389)=-.17 ; \mathrm{p}<.001$ ). There was one scale which showed a significant correlation with the time-of-day: Fear of Negative Evaluation (Pearson's $\mathrm{r}(340)=.12 ; \mathrm{p}=.027)$. However, it didn't hold after Bonferroni correction (like other correlations with time-of-day). 
Table 2: Demographic traits' correlations with time-of-semester \& time-of-day

time-of-semester time-of-day

\begin{tabular}{|c|c|c|c|c|c|c|}
\hline trait & & $\mathrm{r}$ & $\mathrm{p}$ & $\mathrm{r}$ & $\mathrm{p}$ & $\mathrm{N}$ \\
\hline \multirow[t]{16}{*}{ Demographic } & Gender & $-0.11 *$ & 0.016 & $-0.12 *$ & 0.009 & 485 \\
\hline & Age & $-0.09 *$ & 0.050 & $-0.13 *$ & 0.004 & 485 \\
\hline & Race & 0.04 & 0.330 & 0.07 & 0.105 & 485 \\
\hline & US born & $0.12 *$ & 0.007 & -0.02 & 0.600 & 485 \\
\hline & Years in US & $0.11 *$ & 0.015 & -0.04 & 0.382 & 485 \\
\hline & GPA high school & $-0.09 *$ & 0.041 & $<0.01$ & 0.909 & 483 \\
\hline & Parents Education & 0.06 & 0.163 & -0.01 & 0.825 & 485 \\
\hline & Parents Job & 0.03 & 0.695 & 0.09 & 0.287 & 144 \\
\hline & Mother Education & 0.08 & 0.075 & $<0.01$ & 0.980 & 485 \\
\hline & Father Education & 0.03 & 0.472 & -0.05 & 0.250 & 478 \\
\hline & Mother Job & 0.08 & 0.363 & 0.05 & 0.608 & 118 \\
\hline & Father Job & $<0.01$ & 0.993 & 0.12 & 0.158 & 130 \\
\hline & Family Income & $0.15 *$ & 0.001 & 0.03 & 0.450 & 485 \\
\hline & Family Size & -0.02 & 0.612 & 0.03 & 0.523 & 485 \\
\hline & SES & $0.13 *$ & 0.004 & 0.03 & 0.546 & 485 \\
\hline & Subjective SES & -0.06 & 0.217 & 0.09 & 0.054 & 485 \\
\hline
\end{tabular}

* significant at $\mathrm{p}<0.05$

** significant after Bonferroni Correction 
Table 3: Big Five personality traits' correlations with time-of-semester \& time-of-day

\begin{tabular}{|c|c|c|c|c|c|c|}
\hline \multirow[b]{2}{*}{ trait } & & \multicolumn{2}{|c|}{ time-of-semester } & \multicolumn{2}{|c|}{ time-of-day } & \multirow[b]{2}{*}{$\mathrm{N}$} \\
\hline & & $\mathrm{r}$ & $\mathrm{p}$ & $\mathrm{r}$ & $\mathrm{p}$ & \\
\hline \multirow[t]{35}{*}{ Big Five } & Neuroticism & 0.04 & 0.604 & 0.04 & 0.572 & 220 \\
\hline & - N1 Anxiety & -0.02 & 0.730 & 0.04 & 0.545 & 220 \\
\hline & - N2 Anger & 0.12 & 0.065 & 0.05 & 0.467 & 220 \\
\hline & - N3 Depression & 0.04 & 0.603 & 0.05 & 0.500 & 220 \\
\hline & - N4 Self-Consciousness & 0.02 & 0.732 & 0.09 & 0.166 & 220 \\
\hline & - N5 Immoderation & -0.04 & 0.520 & -0.06 & 0.384 & 220 \\
\hline & - N6 Vulnerability & 0.02 & 0.804 & -0.02 & 0.813 & 220 \\
\hline & Extraversion & 0.08 & 0.233 & -0.02 & 0.755 & 220 \\
\hline & - E1 Friendliness & 0.07 & 0.271 & 0.04 & 0.556 & 220 \\
\hline & - E2 Gregariousness & $0.19 *$ & 0.005 & 0.01 & 0.937 & 220 \\
\hline & - E3 Assertiveness & -0.05 & 0.479 & 0.04 & 0.508 & 220 \\
\hline & - E4 Activity Level & -0.03 & 0.696 & -0.05 & 0.457 & 220 \\
\hline & - E5 Excitement Seeking & 0.11 & 0.111 & -0.08 & 0.255 & 220 \\
\hline & - E6 Cheerfulness & $<0.01$ & 0.993 & -0.06 & 0.380 & 220 \\
\hline & Openness to Experience & $-0.14 *$ & 0.038 & 0.04 & 0.535 & 220 \\
\hline & - O1 Imagination & -0.07 & 0.317 & 0.06 & 0.368 & 220 \\
\hline & - O2 Artistic Interests & -0.13 & 0.061 & -0.04 & 0.584 & 220 \\
\hline & - O3 Emotionality & -0.04 & 0.523 & 0.10 & 0.154 & 220 \\
\hline & - O4 Adventurousness & 0.02 & 0.769 & -0.01 & 0.914 & 220 \\
\hline & - O5 Intellect & -0.10 & 0.122 & 0.04 & 0.533 & 220 \\
\hline & - O6 Liberalism & $-0.18 *$ & 0.009 & -0.01 & 0.927 & 220 \\
\hline & Agreeableness & $-0.18 *$ & 0.008 & -0.06 & 0.393 & 220 \\
\hline & - A1 Trust & -0.02 & 0.732 & 0.03 & 0.648 & 220 \\
\hline & - A2 Morality & $-0.15 *$ & 0.029 & 0.01 & 0.918 & 220 \\
\hline & - A3 Altruism & -0.11 & 0.091 & 0.03 & 0.609 & 220 \\
\hline & - A4 Cooperation & $-0.24 * *$ & $<.001$ & -0.13 & 0.063 & 220 \\
\hline & - A5 Modesty & -0.03 & 0.658 & -0.09 & 0.165 & 220 \\
\hline & - A6 Sympathy & $-0.14 *$ & 0.032 & -0.06 & 0.370 & 220 \\
\hline & Conscientiousness & $-0.21 *$ & 0.001 & -0.09 & 0.161 & 220 \\
\hline & - C1 Self Efficacy & -0.11 & 0.118 & -0.10 & 0.134 & 220 \\
\hline & - C2 Orderliness & -0.11 & 0.120 & -0.07 & 0.277 & 220 \\
\hline & - C3 Dutifulness & $-0.17 *$ & 0.010 & -0.03 & 0.612 & 220 \\
\hline & - C4 Achievement Striving & $-0.25^{* *}$ & $<.001$ & -0.10 & 0.159 & 220 \\
\hline & - C5 Self Discipline & $-0.20 *$ & 0.003 & -0.09 & 0.177 & 220 \\
\hline & - C6 Cautiousness & -0.11 & 0.118 & -0.02 & 0.821 & 220 \\
\hline
\end{tabular}

* significant at $\mathrm{p}<0.05$

** significant after Bonferroni Correction 
Table 4: "Other Personality" traits' correlations with time-of-semester \& time-of-day

\begin{tabular}{|c|c|c|c|c|c|c|}
\hline \multirow[b]{2}{*}{ trait } & & \multicolumn{2}{|c|}{ time-of-semester } & \multicolumn{2}{|c|}{ time-of-day } & \multirow[b]{2}{*}{$\mathrm{N}$} \\
\hline & & $\mathrm{r}$ & $\mathrm{p}$ & $\mathrm{r}$ & $\mathrm{p}$ & \\
\hline Grit Scale & & $-0.26 * *$ & $<.001$ & -0.07 & 0.206 & 342 \\
\hline \multirow[t]{7}{*}{ DPES } & Joy & 0.01 & 0.866 & 0.01 & 0.862 & 219 \\
\hline & Contentment & -0.04 & 0.584 & 0.01 & 0.941 & 219 \\
\hline & Pride & -0.09 & 0.198 & -0.06 & 0.414 & 219 \\
\hline & Love & 0.04 & 0.562 & 0.04 & 0.606 & 219 \\
\hline & Compassion & $-0.19 *$ & 0.006 & 0.02 & 0.787 & 219 \\
\hline & Amusement & -0.06 & 0.397 & -0.10 & 0.157 & 219 \\
\hline & Awe & -0.10 & 0.127 & -0.10 & 0.131 & 219 \\
\hline Personal Need for Structure & & 0.03 & 0.646 & 0.09 & 0.195 & 219 \\
\hline Life History & Mini-K & -0.03 & 0.479 & $<0.01$ & 0.917 & 481 \\
\hline LOT-R & & $-0.11^{*}$ & 0.037 & -0.04 & 0.465 & 342 \\
\hline
\end{tabular}

* significant at $\mathrm{p}<0.05$

** significant after Bonferroni Correction 
Table 5: "Cognitive” traits' correlations with time-of-semester \& time-of-day

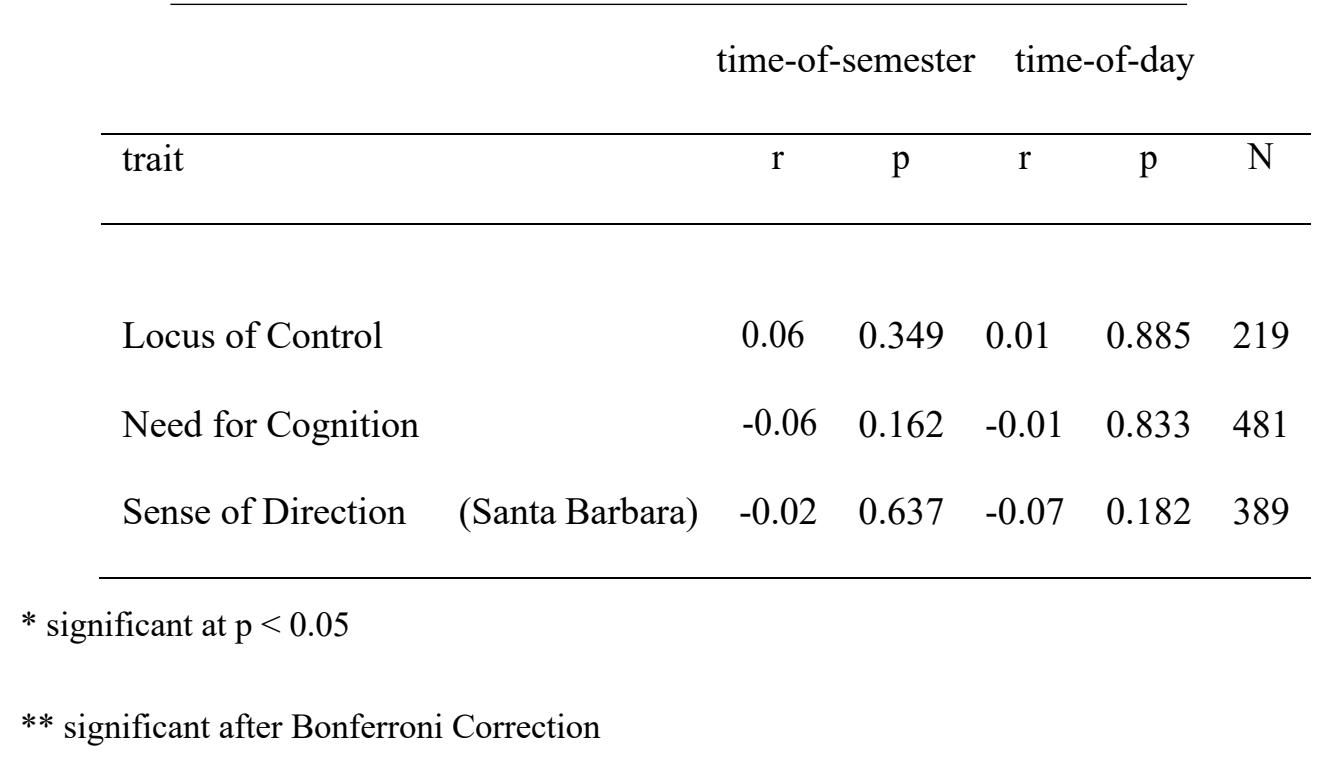


Table 6: "Decision-making” traits' correlations with time-of-semester \& time-of-day

\begin{tabular}{|c|c|c|c|c|c|c|}
\hline \multirow[b]{2}{*}{ trait } & \multicolumn{4}{|c|}{ time-of-semester } & \multirow[b]{2}{*}{$\mathrm{p}$} & \multirow[b]{2}{*}{$\mathrm{N}$} \\
\hline & & $\mathrm{r}$ & $\mathrm{p}$ & $\mathrm{r}$ & & \\
\hline \multirow[t]{3}{*}{ Sensation Seeking } & & $0.26 * *$ & $<.001$ & -0.02 & 0.658 & 391 \\
\hline & Novelty & $0.28 * *$ & $<.001$ & -0.04 & 0.379 & 391 \\
\hline & Intensity & $0.16 *$ & 0.001 & 0.01 & 0.906 & 391 \\
\hline Financial Risk Tolerance & & 0.08 & 0.234 & $<0.01$ & 0.950 & 249 \\
\hline \multirow[t]{10}{*}{ BIS-11 } & & $0.14 *$ & 0.004 & 0.03 & 0.579 & 393 \\
\hline & Attentional & $0.11 *$ & 0.024 & 0.05 & 0.311 & 393 \\
\hline & - Attention & $0.18 *$ & $<.001$ & 0.02 & 0.661 & 393 \\
\hline & - Cognitive Instability & -0.02 & 0.625 & 0.07 & 0.172 & 393 \\
\hline & Motor & 0.08 & 0.116 & 0.02 & 0.662 & 393 \\
\hline & - Motor & 0.07 & 0.163 & 0.01 & 0.807 & 393 \\
\hline & - Perseverance & 0.06 & 0.239 & 0.03 & 0.547 & 393 \\
\hline & Nonplanning & $0.14 *$ & 0.004 & $<0.01$ & 0.997 & 393 \\
\hline & - Self Control & $0.16 *$ & 0.001 & -0.02 & 0.717 & 393 \\
\hline & - Cognitive Complexity & 0.07 & 0.150 & 0.02 & 0.651 & 393 \\
\hline \multirow[t]{4}{*}{ Tolerance of Ambiguity } & & -0.04 & 0.490 & $0.11 *$ & 0.027 & 391 \\
\hline & Novelty & -0.01 & 0.799 & 0.06 & 0.222 & 391 \\
\hline & Complexity & -0.02 & 0.668 & 0.08 & 0.095 & 391 \\
\hline & Insolubility & -0.04 & 0.462 & 0.06 & 0.230 & 391 \\
\hline \multirow[t]{3}{*}{$\mathrm{I} / \mathrm{D}$} & & -0.04 & 0.589 & $<0.01$ & 0.967 & 219 \\
\hline & Interest-Type & -0.07 & 0.315 & -0.03 & 0.639 & 219 \\
\hline & Deprivation-Type & $<0.01$ & 0.959 & 0.03 & 0.701 & 219 \\
\hline \multirow[t]{3}{*}{ CEI-II } & & -0.05 & 0.470 & -0.08 & 0.260 & 219 \\
\hline & Stretching & -0.07 & 0.330 & -0.04 & 0.516 & 219 \\
\hline & Embracing & -0.02 & 0.722 & -0.09 & 0.174 & 219 \\
\hline Temporal Discounting & & -0.05 & 0.429 & -0.08 & 0.234 & 220 \\
\hline
\end{tabular}

* significant at $\mathrm{p}<0.05$

** significant after Bonferroni Correction 
Table 7: "Social" traits' correlations with time-of-semester $\&$ time-of-day

time-of-semester time-of-day

\begin{tabular}{|c|c|c|c|c|c|c|}
\hline trait & & $\mathrm{r}$ & $\mathrm{p}$ & $\mathrm{r}$ & $\mathrm{p}$ & $\mathrm{N}$ \\
\hline \multirow[t]{4}{*}{ IRI } & Perspective Taking & $-0.15 *$ & 0.001 & 0.03 & 0.514 & 481 \\
\hline & Fantasy & $-0.11 *$ & 0.018 & -0.04 & 0.405 & 481 \\
\hline & Empathic Concern & $-0.17^{* *}$ & $<.001$ & 0.04 & 0.368 & 481 \\
\hline & Personal Distress & $0.10 *$ & 0.028 & $<0.01$ & 0.923 & 481 \\
\hline \multirow[t]{3}{*}{ Competitiveness } & & 0.02 & 0.688 & -0.06 & 0.168 & 481 \\
\hline & Enjoyment of Competition & -0.01 & 0.816 & -0.07 & 0.128 & 481 \\
\hline & Contentiousness & 0.06 & 0.162 & -0.02 & 0.627 & 481 \\
\hline Fear of Negative Evaluation & & -0.10 & 0.067 & $0.12 *$ & 0.027 & 342 \\
\hline \multirow[t]{3}{*}{ Conservatism } & & 0.06 & 0.269 & -0.04 & 0.488 & 341 \\
\hline & Economic & 0.10 & 0.066 & 0.01 & 0.823 & 341 \\
\hline & Social & 0.02 & 0.708 & -0.06 & 0.309 & 341 \\
\hline \multirow[t]{2}{*}{ Individualism } & Horizontal & -0.08 & 0.154 & -0.06 & 0.292 & 337 \\
\hline & Vertical & 0.08 & 0.152 & -0.08 & 0.127 & 337 \\
\hline \multirow[t]{2}{*}{ Collectivisim } & Horizontal & $-0.15^{*}$ & 0.005 & -0.02 & 0.734 & 337 \\
\hline & Vertical & -0.02 & 0.740 & -0.07 & 0.205 & 337 \\
\hline
\end{tabular}

* significant at $\mathrm{p}<0.05$

** significant after Bonferroni Correction 


\section{Analysis of Variance}

To test for possible non-monotonic relationships between time of semester and personality traits, we performed an ANOVA. In particular, we discretized time of semester based on week (from 1 to 13) and asked whether there was an effect of group on trait.

Table S2 (Supplementary Materials D) shows the results of this analysis for those traits that yielded a significant $\mathrm{F}$ value. These results are not the same as what we obtained through a simple Pearson correlation (A4-Cooperation and C4-Achievement Striving didn't show up here for example), but the overall scheme is similar, specifically for the Grit scale and Arnett sensation seeking which shows the largest $F$ value and significance at $\mathrm{p}<0.001$.

Figure 1 shows the plot of means of the six variables that remained after Bonferroni correction in our correlation analysis: Grit Scale, Arnett Sensation Seeking (and its Novelty sub-scale), C4-Achievement Striving, A4-Cooperation, and IRI-Empathic Concern. One interesting point from this plot is the non-linear pattern of Arnett Sensation Seeking through the semester: it seems to follow a half- semester time period than a full one. The average score for sensation seeking is comparatively low at the beginning of semester and it goes up until around the mid-term (week 6). Then it goes down sharply to the level of week 1 and again gradually goes up through week 13. 

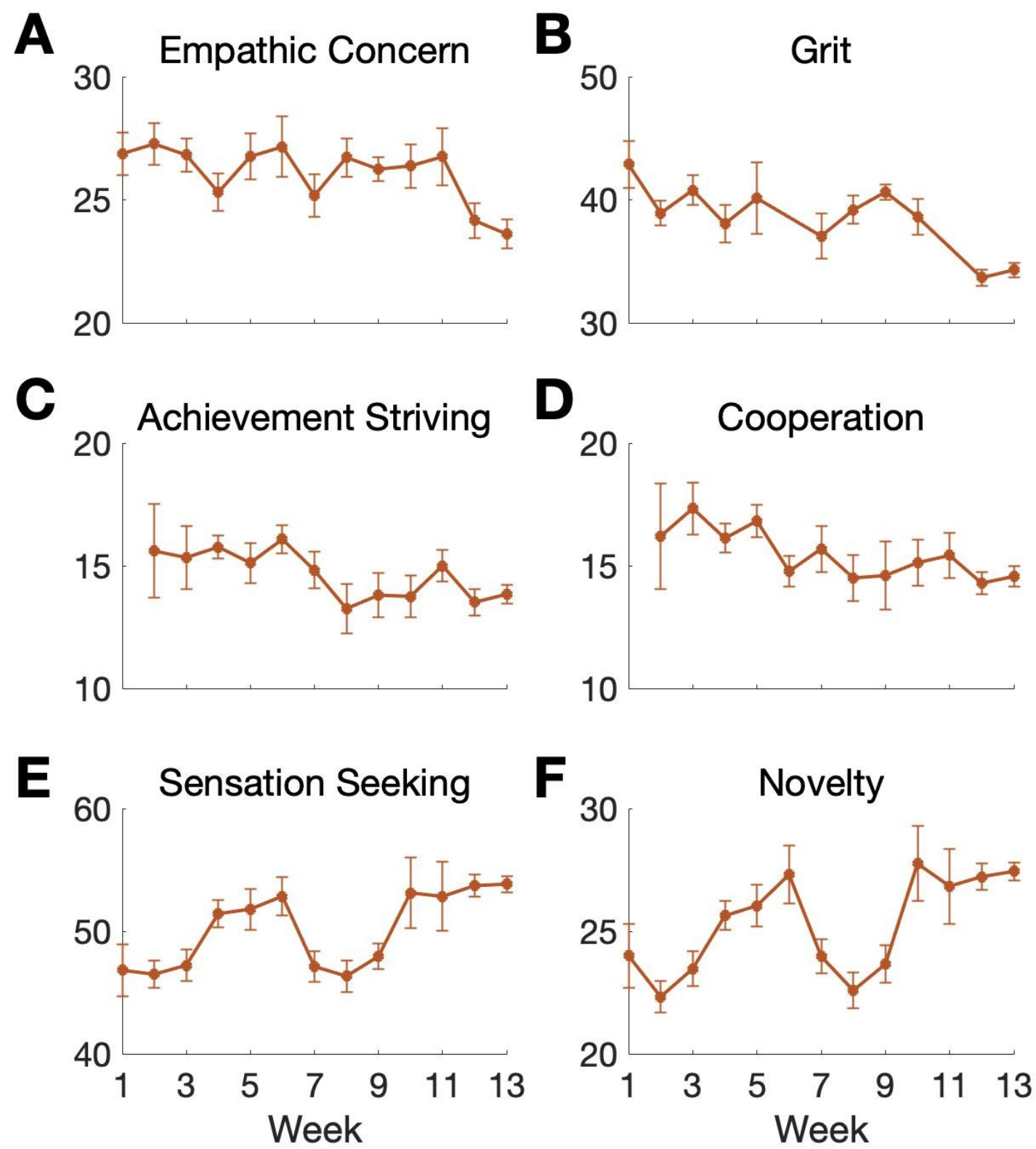

Figure 1: Changes in (A) IRI - Empathic Concern, (B) Grit Scale, (C) A4 - Achievement Striving, (D) C4 - Cooperation, (E) Arnett Sensation Seeking - total, and (F) Arnett Sensation Seeking - Novelty through the semester (Weeks 1-13). The bars represent the standard errors of the means (sem), i.e. error bars. 


\section{Controlling for gender}

Since females and males have different personality traits and they tend to participate in different time-of-semester, the correlations between time-of-semester and personality traits might be due to gender differences in personality. To take this notation into account, we calculated partial correlations between traits and time-of-semester, controlling for gender. The results (Supplementary Materials E) are almost similar to the original results (Tables 1-6), especially in the Grit Scale, Arnett Sensation seeking and IRI-Empathic concern. Supplementary Materials E - Table S3 shows the significant partial correlations $(\mathrm{p}<0.05$, no multiple comparison correction). 


\section{Discussion}

In this paper, we investigated time-of-semester and time-of-day effects on demographic and personality variables in the psychology subject pool at $[-]$, a large public school in the US. Overall, we found a similar demographic/personality profile mentioned in previous studies with some differences and new findings.

Consistent with previous work we found that early participants were more likely to be female, more Conscientious, more Agreeable, more Open, and less Extroverted than those who participated late in the semester. Such a pattern is consistent with the Good Student Effect (Zelenski et al., 2003), whereby early participants are better students, and lends weight to earlier studies.

In contrast to previous work, we found no correlation of time-of-semester with temporal discounting (Cassidy \& Kangas, 2014) and Personal Need for Structure (PNS) (Roman, Moskowitz, Stein, \& Eisenberg, 1995). Indeed, even without correction for multiple comparisons, there was no relationship between time-of-semester and these variables. For temporal discounting, the discrepancy might be due to using a different measure. In our experiment, participants picked between "today" and "later" options in 27 scenarios with varying rewards and delays (Kirby, Petry, \& Bickel, 1999). In contrast, Cassidy and Kangas (2014) used a different procedure in which the future reward was always fixed at $\$ 100$ and participants reported the delay (between 1 week and 8 years) at which they would be indifferent be-tween the two options. Also, while our task was presented in a short survey form, in their procedure are search assistant was heavily involved in verbal presentation of each scenario and finding the point of indifference on screen. These major differences hold us from drawing a straightforward speculation on the observed discrepancy. For the PNS, Roman et al. (1995) used the same measure as ours 
(Neuberg \& Newsom, 1993), but there are differences in time (more than 20 years distance between two experiments) and context (New York vs Tucson) that may contribute to the observed discrepancy.

We also found evidence that two novel traits are associated with time of semester, both of which stand after Bonferroni correction for multiple comparisons. The first is Grit, which is a measure of perseverance and resilience, and was developed to describe the personal qualities essential to high achievement. It is defined as the passion for long-term goals and persistence in working toward these goals despite adversity or failure (Duckworth et al., 2007). As such, the Grit concept fits very well with the "good student" effect (Zelenski et al., 2003).

Consistent with our finding for Grit, several overlapping constructs have also been shown correlated with time-of-semester. For example, Strube and Ota (1982) reported that type A personality trait (which is related to being more competitive, more ambitious and highly organized) are found higher in early than late participants. Richert and Ward (1976) reported a decline in participants' self-esteem over the course of semester. Also, it has been found that early participants spent more time on filling questionnaires than late participants which has been interpreted by some researchers as their greater seriousness of purpose (Mulry \& Dunbar, n.d.; cited in Rosenthal \& Rosnow, 1975). In the present study, we found that Conscientiousness (and more strongly its subscale Achievement Striving) also decreased over the course of the semester and, in line with previous work (Duckworth et al., 2007) we found a significant correlation between Conscientiousness and Grit $(\mathrm{r}(78)=0.29 ; \mathrm{p}=0.0089)$. In their metanalysis, Credé, Tynan, \& Harms $(2017)$ found a much stronger correlation between Grit and Conscientiousness $(\mathrm{k}=22, \mathrm{~N}=$ $18,826, \rho=.84, \mathrm{SD} \rho=.07)$. This suggests that Grit may be just Conscientiousness in disguise and our finding that Grit correlates with time-of-semester is just a replication of 
previous findings that Conscientiousness correlates with time-of-semester.

The second trait that varies with time of semester, Arnett Sensation Seeking, does not fit so cleanly with the "good student" effect. In particular, rather than a monotonic decline in Sensation Seeking through the semester (as one might expect if 'good students' were less sensation seeking), we found a non-monotonic relation with time-of-semester with Sensation Seeking peaking in the middle as well as the end of the semester (Figure 1E, F). One possible explanation for this is that sensation-seekers seek partying in college and the parties' schedules in colleges seem to distribute unevenly throughout the semester (more partying in the beginning of semester and after midterms). Another related parameter involved is short vacations in the middle of semester: fall and spring breaks. The important note here is that for some traits like sensation seeking, a linear assumption might be misleading, and we need to consider the pattern of changes during semester to better detect any time-of-semester effects, if there is one.

So, after all, does any of this matter? Should we control for time-of-semester and timeof-day effects 14 when running a study? On the one hand, most of the effects we measured were small and (statistically)insignificant even at the liberal thresholds without correcting for multiple comparisons. Thus, for many studies, acquisition over a short period of time in the semester is unlikely to lead to major bias. However, for other studies, where the focus is on constructs related to Grit, Sensation Seeking or the other measures we found above, more care may be required, especially when the anticipated effect sizes may be small (Meyer et al., 2001).

Funding: The authors have no funding to disclose.

Compliance with Ethical Standards: All procedures performed in experiments were in accordance with the ethical standards of the institutional research committee and with the 
1964 Helsinki Declaration and its later amendments or comparable ethical standards.

Conflicts of Interest: The authors declare that they have no conflict of interest.

Informed Consent: Informed consent was obtained from all individual adult participants included in the study.

\section{Authors Contributions Statement:}

HS, SW, and RCW designed the experiments. HS, HMK, MRA, SS, and KLK ran the experiments. HS analyzed the data with supervision from RCW. HS and RCW wrote the manuscript with input from all other authors.

Data Availability Statement: All the data and MATLAB codes for the analyses are available at https://github.com/hashem20/time-of-semester

\section{References}

Adair, J. (1973). The human subject: The social psychology of the psychological experiment. Boston: Little Brown \& Co.

Arnett, J. (1994). Sensation seeking: A new conceptualization and a new scale. Personality and Individual Differences, 16(2), 289-296.

Aviv, A. L., Zelenski, J. M., Rallo, L., \& Larsen, R. J. (2002). Who comes when: Personality differences in early and later participation in a university subject pool. Personality and Individual Differences, 33(3), 487-496.

Cacioppo, J. T., \& Petty, R. E. (1982). The need for cognition. Journal of Personality and Social Psychology, 42(1), 116-131.

Cassidy, R. N., \& Kangas, B. D. (2014). Impulsive students participate later: delay discounting in a research subject pool. Experimental Analysis of Human Behavior Bulletin, 30(2003),1-5.

Cooper, H., Baumgardner, A. H., \& Strathman, A. (1991). Do Students with Different Characteristics Take Part in Psychology Experiments at Different Times of the 
Semester? Journal of Personality, 59(1), 109-127.

Credé, M., Tynan, M. C., \& Harms, P. D. (2017). Much ado about grit: A meta-analytic synthesis of the grit literature. Journal of Personality and Social Psychology, 113(3), 492.

Davis, M. H. (1983). Measuring individual differences in empathy: Evidence for a multidimensional approach. Journal of Personality and Social Psychology, 44(1), 113-126.

Duckworth, A. L., Peterson, C., Matthews, M. D., \& Kelly, D. R. (2007). Grit: Perseverance and passion for long-term goals. Journal of Personality and Social Psychology, 92(6), $1087-1101$.

Ebersole, C. R., Atherton, O. E., Belanger, A. L., Skulborstad, H. M., Allen, J. M., Banks, J. B., .. . Nosek, B. A. (2016). Many Labs 3: Evaluating participant pool quality across the academic semester via replication. Journal of Experimental Social Psychology, 67, $68-82$.

Evans, R., \& Donnerstein, E. (1974). Some implications for psychological research of early versus late term participation by college subjects. Journal of Research in Personality, 8(1), 102-109.

Everett, J. A. (2013). The 12 Item Social and Economic Conservatism Scale (SECS). PLoS ONE, 8(12), e82131.

Figueredo, A. J., Vásquez, G., Brumbach, B. H., Schneider, S. M., Sefcek, J. A., Tal, I. R., . . .Jacobs, W. J. (2006). Consilience and Life History Theory: From genes to brain to reproductive strategy. Developmental Review, 26(2), 243-275.

Findley, M., \& Cooper, H. (1981). Introductory Social Psychology Textbook Citations: A Comparison in Five Research Areas. Personality and Social Psychology Bulletin, 7(1), $173-176$.

Grable, J., \& Lytton, R. H. (1999). Financial risk tolerance revisited: the development of a 
risk assessment instrument. Financial Services Review, 8(3), 163-181.

Greene, W. A., \& Sutor, L. T. (1971). Stimulus control of skin resistance responses on an escape-avoidance schedule. Journal of the experimental analysis of behavior, 16(2), 269-274.

Groppe, D. (2020). Bonferroni-Holm Correction for Multiple Comparisons (https://www.mathworks.com/matlabcentral/fileexchange/28303-bonferroni-holmcorrection-for-multiple-comparisons), MATLAB Central File Exchange. Retrieved March 16, 2020.

Harris, P. B., \& Houston, J. M. (2010). A reliability analysis of the Revised Competitiveness Index. Psychological Reports, 106(3), 870-874.

Hegarty, M., Montello, D. R., Richardson, A. E., Ishikawa, T., \& Lovelace, K. (2006). Spatial abilities at different scales: Individual differences in aptitude-test performance and spatial-layout learning. Intelligence, 34(2), 151-176.

Higbee, K. L., Millard, R. J., \& Folkman, J. R. (1982). Social psychology research during the 1970s: Predominance of experimentation and college students. Personality and Social Psychology Bulletin, 8(1), 180-183.

Holden, R. R., \& Reddon, J. R. (1987). Temporal personality variations among participants from a university subject pool. Psychological Reports, 60(3c), 1247-1254.

Holm, S. (1979). A simple sequentially rejective multiple test procedure. Scandinavian journal of statistics, 65-70.

Jackson, J. J. M., Procidano, M. M. E., \& Cohen, C. J. C. (1989). Subject pool sign-up procedures: a threat to external validity. Social Behavior and Personality: an international journal, 17(1), 29-42.

Johnson, J. A. (2014). Measuring thirty facets of the Five Factor Model with a 120-item public domain inventory: Development of the IPIP-NEO-120. Journal of Research in 
Personality, 51, 78-89.

Kangas, B. D., \& Hackenberg, T. D. (2009). On reinforcing human behavior in the laboratory: A brief review and some recommendations. Experimental Analysis of Human Behavior Bulletin, 27, 21-26.

Kashdan, T. B., Gallagher, M. W., Silvia, P. J., Winterstein, B. P., Breen, W. E., Terhar, D., \& Steger, M. F. (2009). The curiosity and exploration inventory-II: Development, factor structure, and psychometrics. Journal of Research in Personality, 43(6), 987-998.

Kirby, K. N., Petry, N. M., \& Bickel, W. K. (1999). Heroin addicts have higher discount rates for delayed rewards than non-drug-using controls. Journal of Experimental Psychology: General, 128(1), 78-87.

Landrum, R. E., \& Chastain, G. (1995). Experiment spot-checks: a method for assessing the educational value of undergraduate participation in research. $I R B, 17(4), 4-6$.

Landrum, R. E., \& Chastain, G. D. (1999). Subject pool policies in undergraduate-only departments: Results from a nationwide survey. In Protecting human subjects:

Departmental subject pools and institutional review boards. (pp. 25-42). Washington: American Psychological Association.

Leary, M. R. (1983). A Brief Version of the Fear of Negative Evaluation Scale. Personality and Social Psychology Bulletin, 9(3), 371-375.

Litman, J. A. (2008). Interest and deprivation factors of epistemic curiosity. Personality and Individual Differences, 44(7), 1585-1595.

McCrae, R. R., \& Costa, P. T. (1997). Personality trait structure as a human universal. American Psychologist, 52(5), 509-516.

Meyer, G. J., Finn, S. E., Eyde, L. D., Kay, G. G., Moreland, K. L., Dies, R. R., . . Reed, G. M. (2001). Psychological testing and psychological assessment: A review of evidence and issues. American Psychologist, 56(2), 128-165. 
Miller, A. (1981). A survey of introductory psychology subject pool practices among leading universities. Teaching of Psychology, 8(4), 211-214.

Mulry, R., \& Dunbar, D. (n.d.). Homogeneity of a subject sample: A study of subject motivation. University of Indiana. Neuberg, S. L., \& Newsom, J. T. (1993). Personal Need for Structure: Individual Differences in the Desire for Simple Structure. Journal of Personality and Social Psychology, 65(1), 113-131.

Patton, J. H., Stanford, M. S., \& Barratt, E. S. (1995). Factor structure of the Barrett impulsiveness scale. Journal of Clinical Psychology, 51(6), 768-774.

Richert, A. J., \& Ward, E. F. (1976). Experimental performance and self-evaluation of subjects sampled early, middle, and late in an academic term: Sex and task. Psychological Reports, 39(1), 135-142.

Richter, D., Wilson, S., Milner, M., \& Senter, R. (1981). Some differences among students volunteering as research subjects. Bulletin of the Psychonomic Society,17(6), 261-263.

Roman, R. J., Moskowitz, G. B., Stein, M. I., \& Eisenberg, R. F. (1995). Individual differences in experiment participation: Structure, autonomy, and the time of the semester. Journal of Personality, 63(1), 113-138.

Rosenthal, R., \& Rosnow, R. L. (1975). Primer of methods for the behavioral sciences. John Wiley \& Sons.

Rotter, J. B. (1966). Generalized expectancies for internal versus external control of reinforcement. Psychological monographs: General and applied, 80(1), 1.

Sadeghiyeh, H. (2019). Social Influence, Temporal Discounting and Active-Passive Gap in Explore-Exploit Dilemma, (Doctoral dissertation), University of Arizona, Tucson, USA.

Sadeghiyeh, H., Wang, S., \& Wilson, R. C. (2018). Lessons from a "failed" replication: The importance of taking action in exploration. PsyArXiv. doi:10.31234/osf.io/ue7dx.

Sadeghiyeh, H., Wang, S., Alberhasky, M. R., Kyllo, H. M., Shenhav, A., \& Wilson, R. C. 
(2020). Temporal discounting correlates with directed exploration but not with random exploration. Scientific Reports, 10(1), 1-10.

Scheier, M. F., Carver, C. S., \& Bridges, M. W. (1994). Distinguishing optimism from neuroticism (and trait anxiety, self-mastery, and self-esteem): a reevaluation of the Life Orientation Test. Journal of personality and social psychology, 67(6), 1063.

Shiota, M. N., Keltner, D., \& John, O. P. (2006). Positive emotion dispositions differentially associated with Big Five personality and attachment style. Journal of Positive Psychology, 1(2), 61-71.

Sieber, J. E., \& Saks, M. J. (1989). A census of subject pool characteristics and policies. American Psychologist, 44(7), 1053-1061.

Stanley Budner, N. Y. (1962). Intolerance of ambiguity as a personality variable. Journal of Personality, 30(1), 29-50.

Strube, M. J., \& Ota, S. (1982). Type A coronary-prone behavior pattern: Relationship to birth order and family size. Personality and Social Psychology Bulletin, 8(2), 317-323.

Triandis, H. C., \& Gelfand, M. J. (1998). Converging measurement of horizontal and vertical individualism and collectivism. Journal of personality and social psychology, 74(1), 118.

Wang, A. Y., \& Jentsch, F. G. (1998). Point-of-time effects across the semester: Is there a sampling bias? Journal of Psychology: Interdisciplinary and Applied,132(2), 211-219.

Zelenski, J. M., Rusting, C. L., \& Larsen, R. J. (2003). Consistency in the time of experiment participation and personality correlates: A methodological note. Personality and Individual Differences, 34(4), 547-558. 


\section{Supplementary Materials}

\section{A. Measures}

\section{Demographic questions}

In the demographic questionnaire we asked about participants' gender, age, race/ethnicity, whether born in US or not, how long lived in US, high-school GPA, family size, family income, parents' education, parents' job, and subjective feeling of socio-economic status (SES) (see Supplementary Materials 1). We also calculated a concrete measure of SES by averaging the normalized scores for family income, parents' job and parent's education:

- Gender (Male, Female):

- How old are you (Age)?

- Race/Ethnicity:

- East Asian or Asian American

- Black, Afro-Caribbean, or African American

- Latino or Hispanic American

- Native American or Alaskan Native

- White, Caucasian or Euro-America

- Middle Eastern

- South Asian or Indian American

- Other

- Were you born in the U.S.? (Yes, No)

- For how many years have you lived in the U.S.?

- What was your final high school G.P.A.?

- How many people (including yourself) were in your family's household when you last lived with them? 
- What was your family's yearly household income when you last lived with your parents? (If you still live with your parents, please refer to their income in the past year)

- Select the appropriate option from the dropdown list for your Mother's and Father's level of school completed. If you grew up in a single parent home, indicate your response for your one parent and select N/A for the other:

- Less than 7 th grade

- Junior high / Middle school (9 th grade)

- Partial high school (10th or 11th grade)

- High school graduate

- Partial college (at least one year)

- College education

- Graduate degree

- Select the appropriate option from the dropdown list for your Mother's and Father's occupation. If you grew up in a single parent home, indicate your response for your one parent and select N/A for the other:

- Day laborer, janitor, house cleaner, farm worker, food counter sales, food preparation worker, busboy

- Garbage collector, short-order cook, cab driver, shoe sales, assembly line workers, masons, baggage porter.

- Painter, skilled construction trade, sales clerk, truck driver, cook, sales counter or general office clerk.

- Automobile mechanic, typist, locksmith, farmer, carpenter, receptionist, construction laborer, hair-dresser. 
- Machinist, musician, bookkeeper, secretary, insurance sales, cabinet maker, personnel specialist, welder.

- Supervisor, librarian, aircraft mechanic, artist and artisan, electrician, administrator, military enlisted personnel, buyer.

- Nurse, skilled technician, medical technician, counselor, manager, police and fire personnel, financial manager, physical, occupational, speech therapist.

- Mechanical, nuclear, and electrical engineer, educational administrator, veterinarian, military officer, elementary, high school and special education teacher,

- Physician, attorney, professor, chemical and aerospace engineer, judge, CEO, senior manager, public official, psychologist, pharmacist, accountant.

- Socio-Economic Status (SES): calculated from parents' job, education and family income

- Think of this slider as representing where people stand in our society. At the right of the slider are the people who are the best off, those who have the most money, most education, and best jobs. At the left are the people who are the worst off, those who have the least money, least education, and worst jobs or no job. Please choose the position of the slider $(0-100)$ that best represents where you think you stand on this continuum (Subjective SES)

\section{Big Five (IPIP-NEO-120)}

The IPIP-NEO-120 is a scale used to measure a broad range of different personality traits using 300 questions. The traits correspond to the big five and include neuroticism, extraversion, openness to experience, agreeableness, and conscientiousness. The scale offers a 5-point Likert response system asking participants how well different traits and characteristics describe their personality. The scale response options are 1- very inaccurate, 2- moderately inaccurate, 3- neither accurate nor inaccurate, 4- moderately 
accurate, 5- very accurate. The condensed 120 item version was used because it has similar validity to the full 300 item version ( $\alpha=.66$ versus .73) based on data collected from a large online and in person sample (Johnson, 2014).

\section{Personality-Others}

\subsection{Grit Scale}

The grit scale is a 12-item questionnaire used to measure passion and perseverance towards long term goals. The scale offers a 5-point Likert response system asking participants how well different statements describe them. The scale response options are 1. not like me at all, 2. not much like me, 3. Somewhat like me, 4. mostly like me, 5. very much like me. While some questions are reverse coded, higher scores indicate more grit (Duckworth et al., 2007).3.2. Dispositional Positive Emotion Scale (DPES)The dispositional positive emotion scale is a 38item questionnaire used to measure participant's disposition towards 7 different positive emotions including joy, contentment, pride, love, compassion, amusement and awe. There are 5-6 questions to capture each different emotion. Participants report their level of agreement with each statement on a 7-point Likert scale anchored at (1) "strongly disagree" and (7) "strongly agree." Correlations for the DPES tend to suggest distinct but related constructs (Shiota et al., 2006).

\subsection{Personal Need for Structure}

The personal need for structure scale is a 10 -item questionnaire developed to measure individual differences in how much personal structure participants prefer to have in their lives. All the items are measured on a 6-point Likert scale. The scale asks participants the extent to which they agree or disagree with various statements. The response options are 1. strongly disagree, 2. moderately disagree, 3. Slightly disagree, 4. slightly agree, 5. moderately agree, 6. strongly agree. Though some items are reverse scored, 
higher scores on the scale generally indicate a stronger personal need for structure (Neuberg \&Newsom, 1993).

\subsection{Life History Strategy: Mini-K}

The Mini $\mathrm{K}$ is a 20 item questionnaire used to measure the seven domains of the Arizona Life His-tory Battery (Figueredo et al., 2006): 1-insight, planning, and control; 2family social contact and support; 3-friends social contact and support; 4-general altruism; 5-mother/father relationship quality;6-experiences in close relationships; and 7-religiosity. All items are measured on a 7-point Likert scale where participants are asked how much they agree or disagree with a given statement. Response options include $-3=$ disagree strongly, $-2=$ disagree somewhat, $-1=$ disagree slightly, $0=$ don't know $/$ NA, 1 =agree slightly, 2 = agree somewhat, 3 = agree strongly (Figueredo et al., 2006).

\subsection{Life Orientation Test-Revised (LOT-R)}

The LOT scale is a 10 -item questionnaire used to measure individual differences in general optimism and pessimism. All items are measured on a 5-point Likert scale where participants indicate the extent to which they agree or disagree with statements. Of the 10 items, 4 of them are filler items thus leaving 6 items of importance. Response options include $0=$ strongly disagree, $1=$ disagree, $2=$ neutral, $3=$ agree, $4=$ strongly agree. While some items are reverse scored, higher scores indicate greater optimism (Scheier et al., 1994).

\section{Cognitive}

\subsection{Rotter's Locus of Control}

The Rotter's Locus of Control scale contains 29 items measuring the respondents' tendency to think situations are under their own control or under the control of external events. This scale uses a forced-choice response set which participants choose between an internal or external interpretation. There are 2 different response options to each 
question, which are uniquely crafted for each question. Scoring awards participants, a point for choosing the "external interpretation", meaning higher scores on the scale are associated with a more external locus of control (Rotter, 1966).

\subsection{Need for Cognition}

The need for cognition scale is an 18-item questionnaire used to measure how much participants tend to engage in and enjoy effortful cognitive endeavors. All items are measured on a 5-point Likert scale where participants indicate how well various statements describe themselves. Response options include1. extremely uncharacteristic of me, 2. somewhat uncharacteristic of me, 3. uncertain, 4. Somewhat characteristic of me, 5. extremely characteristic of me. While some questions are reverse scored, higher scores indicate a higher need for cognition (Cacioppo \& Petty, 1982).

\subsection{Santa Barbara Sense of Direction}

The Santa Barbara Sense of Direction Scale is a 15-item questionnaire used to measure the self-reported spatial and navigational abilities, experiences and preferences of participants. The questionnaire asks participants to indicate the extent to which they agree or disagree with certain statements. The response option to each statement includes a 7-point Likert scale anchored at $1=$ strongly disagree and $7=$ strongly agree. While some items are reverse scored, higher scores correspond to a better sense of direction (Hegarty et al., 2006).

\section{Decision-making}

\subsection{Arnett Inventory of Sensation Seeking (AISS)}

The Arnett sensation seeking scale is a 20 -item questionnaire used to measure attitudes towards general sensation seeking. The scale offers a 4-point Likert response system asking participants how well different statements describe them. The scale response options are A. describes me very well, B. describes me somewhat, C. does not describe 
me very well, D. does not describe me at all. While some questions are reverse coded, higher scores indicate a more favorable attitude towards sensation seeking (Arnett, 1994).

\subsection{Financial Risk Tolerance Assessment}

The financial risk tolerance scale is a 20 -item questionnaire used to measure participant's tolerable level of financial risk in different scenarios. The response options are different for each question, but all questions have between 2-4 response options in a Likert style response format. Some questions are reverse coded. Higher scores indicate greater tolerance for financial risk taking (Grable \& Lytton, 1999).

\subsection{Barratt Impulsivity Scale (BIS-11)}

The BIS-11 contains 30 questions measuring impulsiveness. The items are measured on a 4-point Likert scale (1. Never, 2. Occasionally, 3. Often, 4. Always). For most items, option 4. Always indicates the most impulsive response, but there are some reversed items to avoid a response bias. (Patton et al.,1995).

\subsection{Tolerance of Ambiguity}

The tolerance of ambiguity scale is a 16-item questionnaire measuring how tolerant participants are towards situations involving ambiguity. All the items are measured on a five-point scale. The scale asks participants the extent they agree or disagree with the statements on a 7-point Likert scale. The response options are 1. strongly disagree, 2. moderately disagree, 3 . disagree, 4 . neutral, 5. agree, 6. moderately agree, 7 . strongly agree. Higher scores indicate a stronger tolerance towards ambiguity (Stanley Budner, 1962).

\subsection{Interest/Deprivation Epistemic Curiosity Scale (I/D)}

The interest deprivation and epistemic curiosity scale is a 10-item questionnaire developed to measure involved pleasure from discovering new ideas (I type) and 
spending time and effort to acquire a specific answer (D type). Five items measure the I type, and 5 items measure the D type. All the items are measured on a 4-point Likert scale. The response options are 1. almost never, 2. sometimes, 3. often, 4. almost always. Higher scores correspond to more interest and curiosity (Litman, 2008).

\subsection{Curiosity and Exploration Inventory (CEI-II)}

The CEI-II is a 10-item questionnaire used to measure feelings about and behavior towards curiosity and exploration. All the items are measured on a 5-point Likert scale. The response options are 1-very slightly or not at all, 2- a little, 3-moderately, 4- quite a bit, 5- extremely. Higher scores indicate more favorable attitudes towards general curiosity and exploration. The CEI-II has acceptable internal reliability $(\alpha=.86)$ (Kashdan et al., 2009).

\subsection{Temporal Discounting}

Temporal discounting was measured by the Delay Discounting Questionnaire (Kirby et al., 1999). In this questionnaire there are 27 questions asking participants' preferences between two hypothetical monetary rewards: one of which pays immediately but is smaller, and the other pays more but is delayed. For example, one item asks: Do you prefer $\$ 11$ now or $\$ 30$ in 7 days? The amount of sooner-immediate reward ("today" option), later-delayed reward ("later" option) and the delay (in terms of days) vary in those 27 questions ("today" reward between $\$ 11$ - \$80; "later" reward between $\$ 25$ - \$85; Delay between 7 - 186 days). The exact values are reported in (Kirby et al., 1999)-Table 3.

\section{Social}

\subsection{Interpersonal Reactivity Scale (IRI)}

The interpersonal reactivity index is a 28 -item questionnaire used to measure first order factors of perspective taking, fantasy, empathetic concern, and personal distress. The 
questionnaire also collapses into2 higher order factors: general empathy and emotional control. The scale offers a 5-point Likert response system asking participants how well different statement describe them. The scale response anchor points are (A (1) - does not describe me well) and (E (5) - describes me very well). While some questions are reverse coded, higher scores indicate greater general empathy and emotional control (Davis, 1983).

\subsection{Revised Competitiveness}

The revised competitiveness scale is a 14 -item questionnaire used to measure individual differences in competitiveness. The items are separated into two different factors, competitiveness ( 10 items, inter-item $\alpha=.93$, test-retest $r=.85)$ and conscientiousness (4 items, inter-item $\alpha=.82$, test-retest $r=.78$ ). The questionnaire asks participants to indicate the extent which they agree or disagree with certain statements. The response set to each item is a 5 -point Likert scale anchored at $1=$ strongly disagree to $5=$ strongly agree. While some items are reverse scored, higher scores indicate more competitiveness (Harris \& Houston, 2010).

\subsection{Fear of Negative Evaluation}

The fear of negative evaluation scale is a 12 item self-report questionnaire used to measure the individual difference of how much participants experience fear when facing negative evaluations. Responses are collected using a 5-point Likert scale. Response options include $1=$ not at all characteristic of me, $2=$ slightly characteristic of me, $3=$ moderately characteristic of me, $4=$ very characteristic of me, $5=$ extremely characteristic of me. While some items are reverse scored, higher scores indicate greater fearof negative evaluations (Leary, 1983).

\subsection{Social and Economic Conservatism Scale (SECS)}


The SECS is a 12 item self-report questionnaire used to measure attitudes towards various social, economic, and political topics. The scale uses a sliding scale response method and asks participants to indicate how positively or negatively they feel about various topics (e.g. abortion, religion, etc.). The sliding scale is anchored at $0=$ extremely negative to $100=$ extremely positive. Scores of 50 indicate neutral attitudes (Everett, 2013).

\subsection{Collectivism/Individualism}

The individualistic/collectivistic (I/C) scale 2 is a 16-item self-report questionnaire used to measure individual differences in individualistic versus collectivistic tendencies. In addition, the scale measures horizontal versus vertical $(\mathrm{H} / \mathrm{V})$ individualism and collectivism. Participants are asked to indicate the 23extent to which they agree or disagree with the statements. Response options include a 9-point Likert scale. Cronbach's $\alpha$ for the items was: $.81(\mathrm{HI}), .82(\mathrm{VI}), .80(\mathrm{HC}), .73(\mathrm{VC})$; factor loadings .40 to .68 (Triandis \& Gelfand, 1998) 


\section{B. Descriptive Statistics - Histograms}
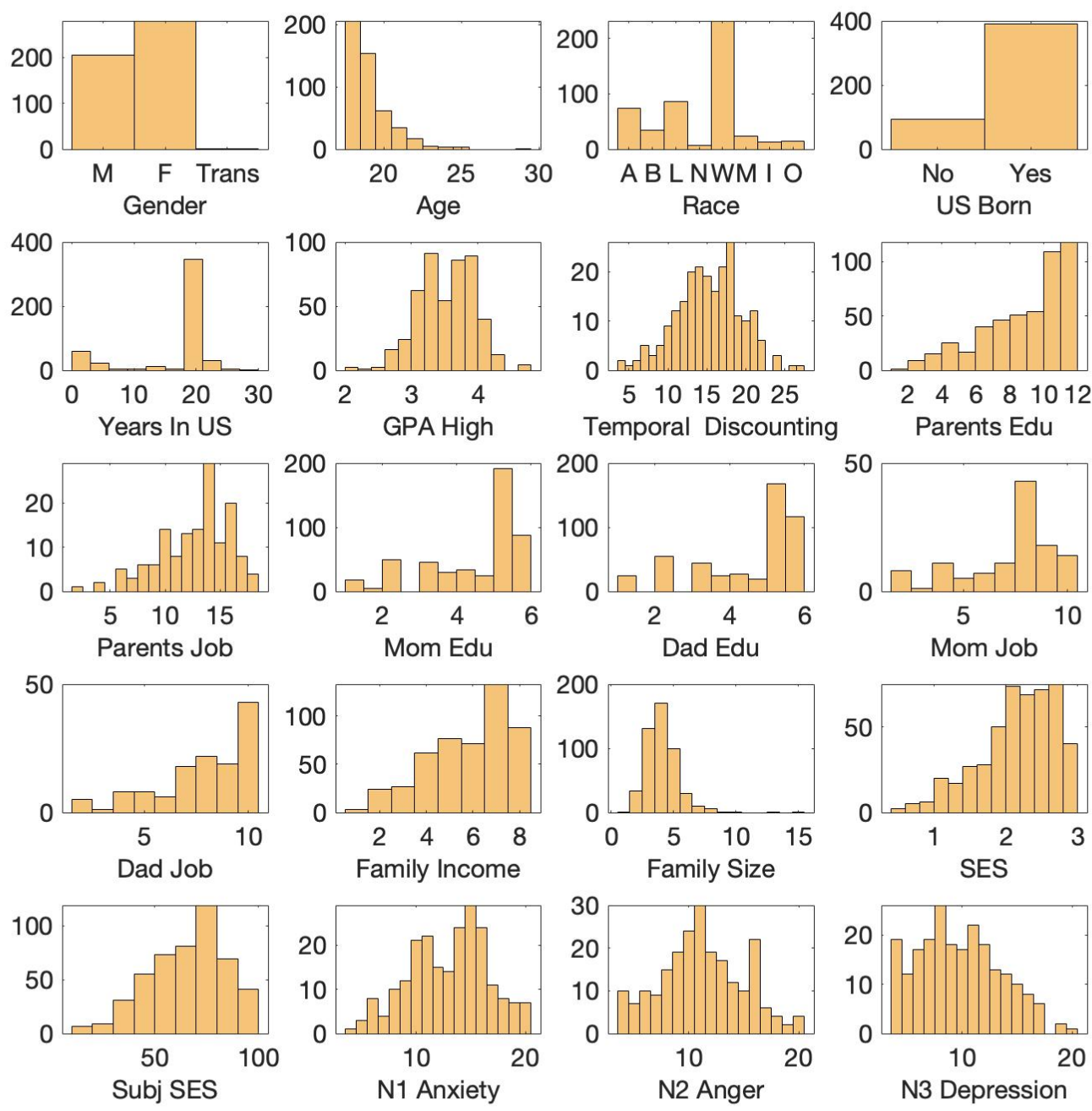

Figure S1 - Histograms demonstrating the distribution of demographic/personality traits in the current study. The y-axis is the frequency or the number of occurrences per each value on the x-axis. For more details about scales of demographic parameters (Parents Job, Parents Education, Family Income, etc.) refer to Supplementary Materials A.1 

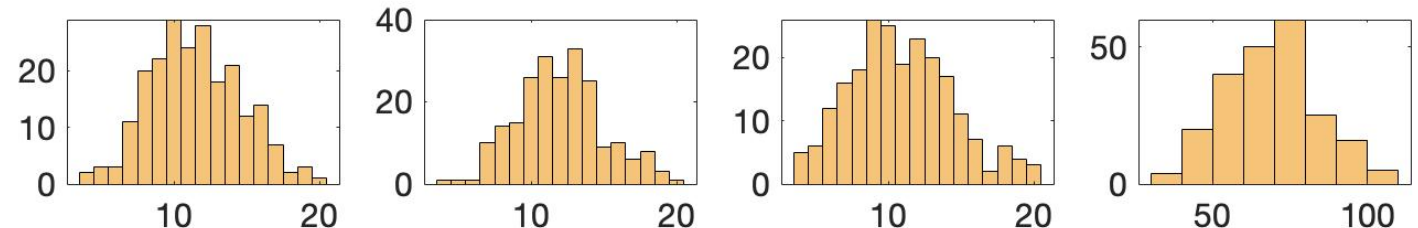

N4 Self Consciousness N5 Immoderation N6: Vulnerability

Neuroticsim
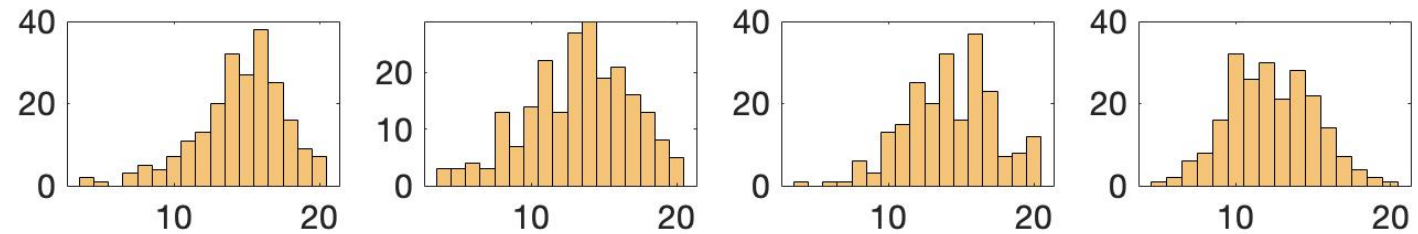

E1 Friendliness
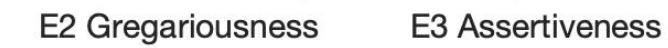

E4 Activity Level
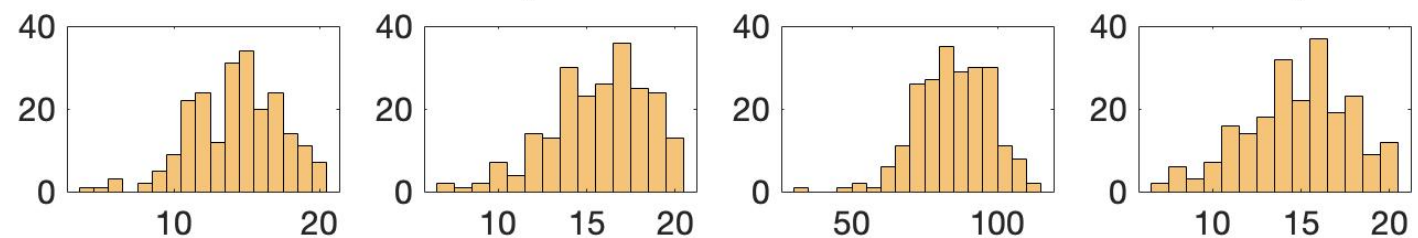

E5 Excitement Seeking
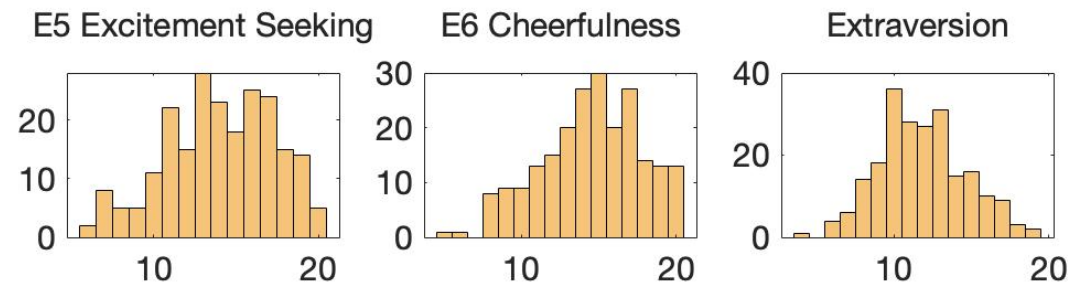

01 Imagination
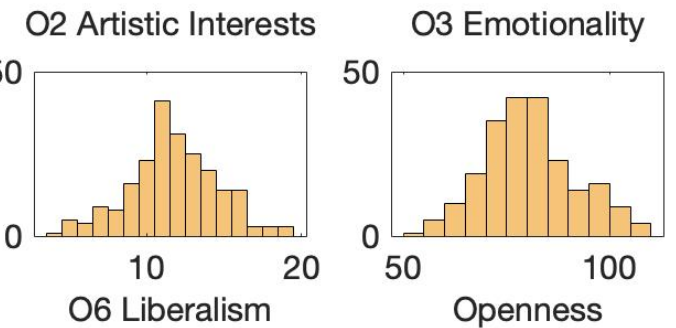

O4 Adventurousness
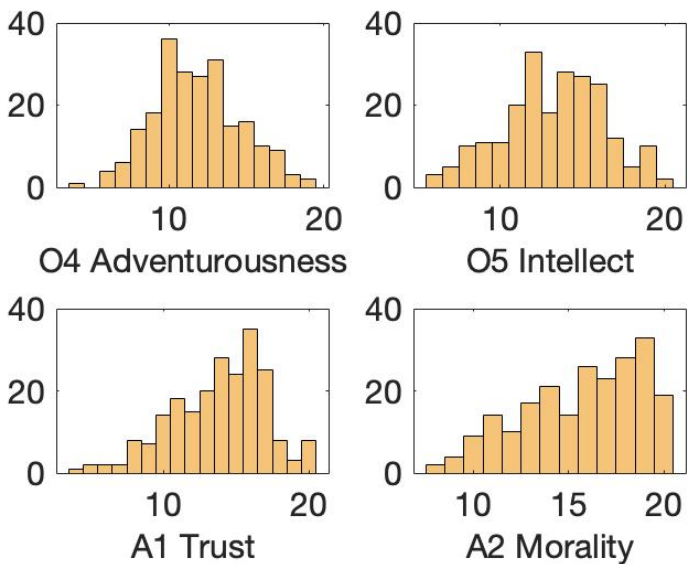

Figure S2 - Histograms demonstrating the distribution of personality traits in the current study. The y-axis is the frequency or the number of occurrences per each value on the $\mathrm{x}$-axis 

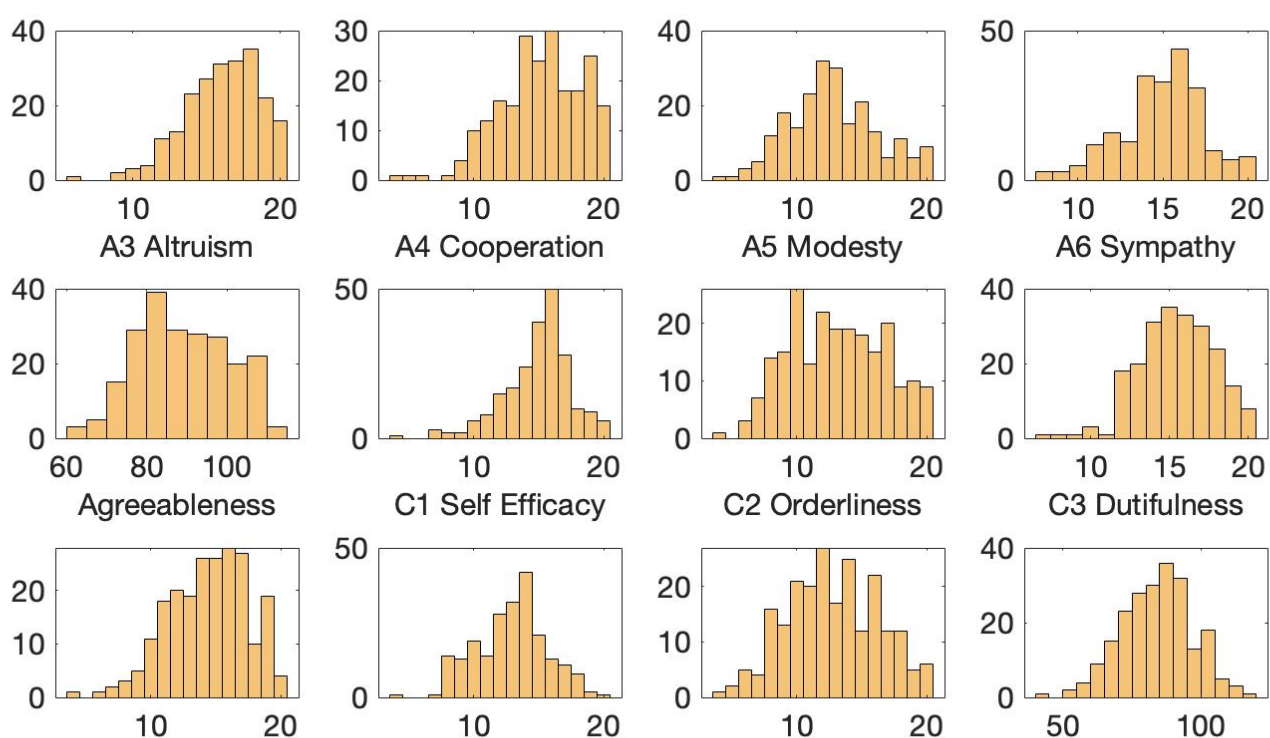

C4 Achievement Striving C5 Self Discipline
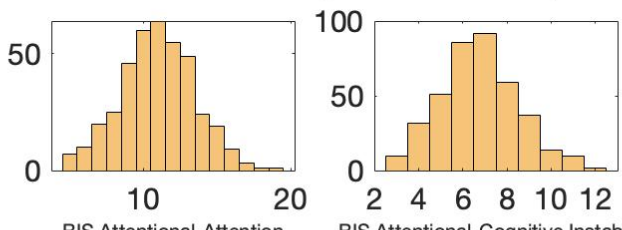

C6 Cautiousness

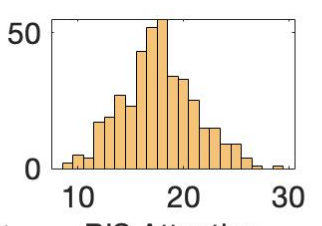

Conscientiousness
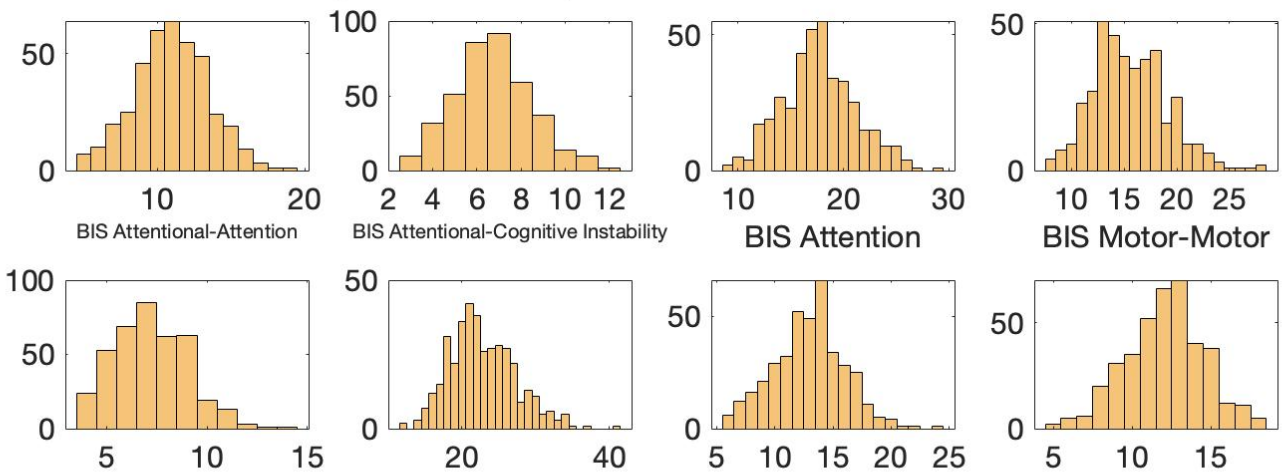

BIS Motor-Perseverance

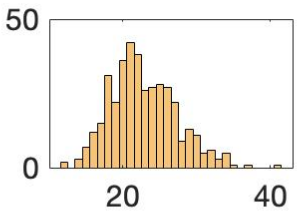

BIS Motor

BIS Nonplanning-Self Control BIS Nonplanning-Cognitive Complexity

Figure S3 - Histograms demonstrating the distribution of personality traits in the current study. The $\mathrm{y}$-axis is the frequency or the number of occurrences per each value on the $\mathrm{x}$-axis 

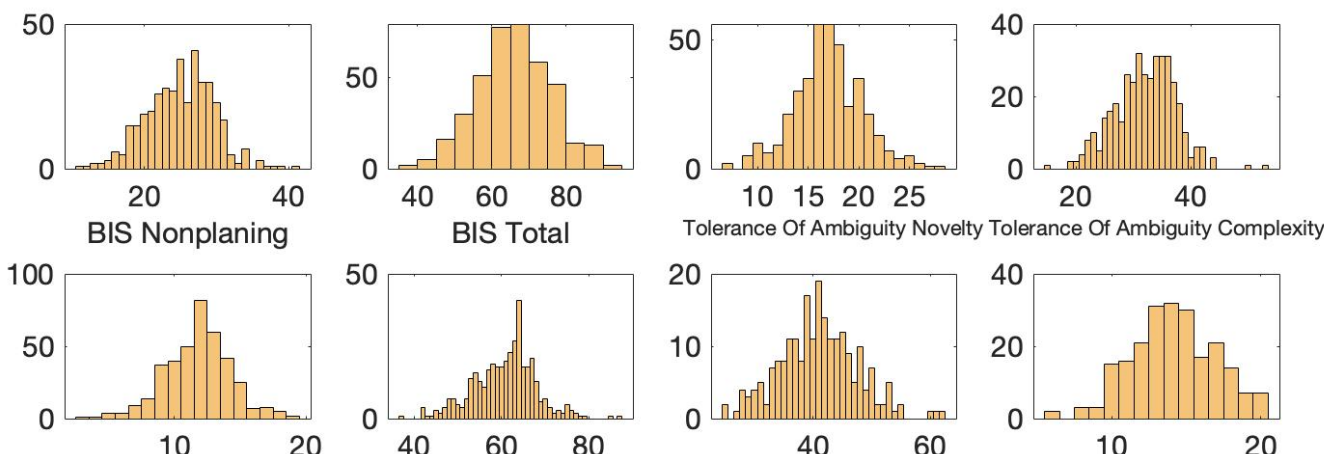

Tolerance Of Ambiguity Nove

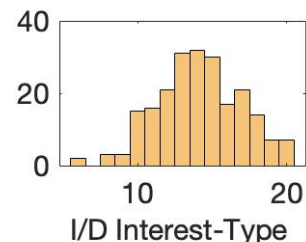

Tolerance Of Ambiguity Insolubility Tolerance Of Ambiguity Total
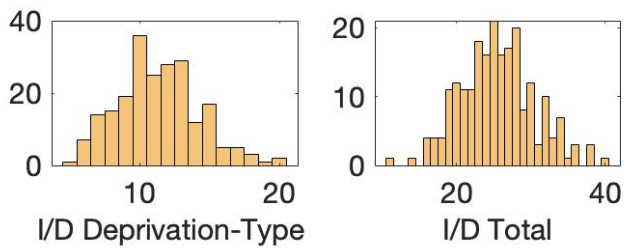

I/D Total
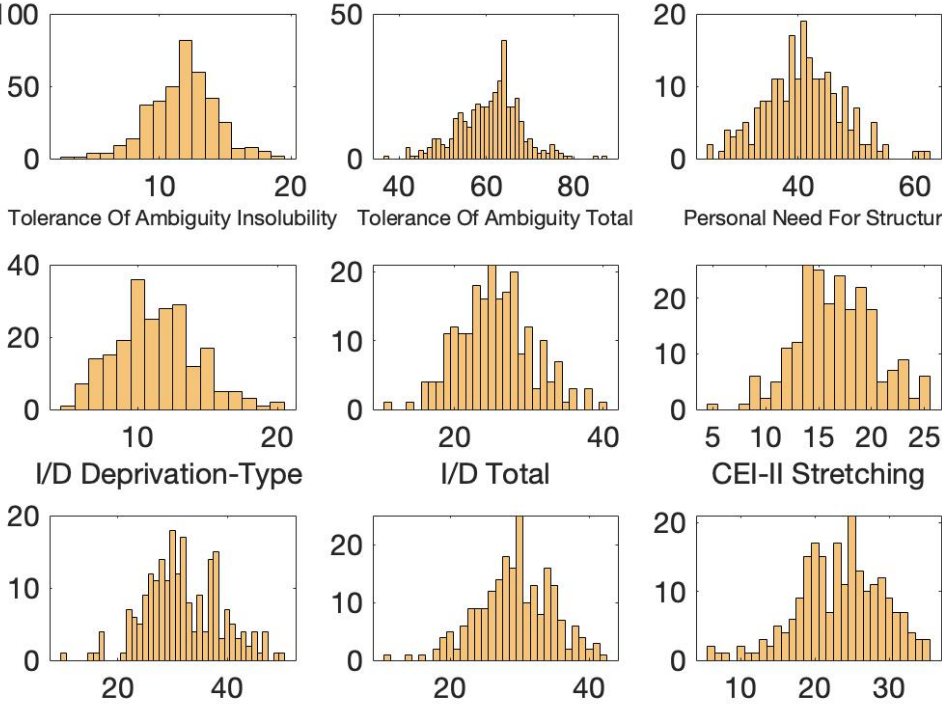

Personal Need For Structure I/D Interest-Type
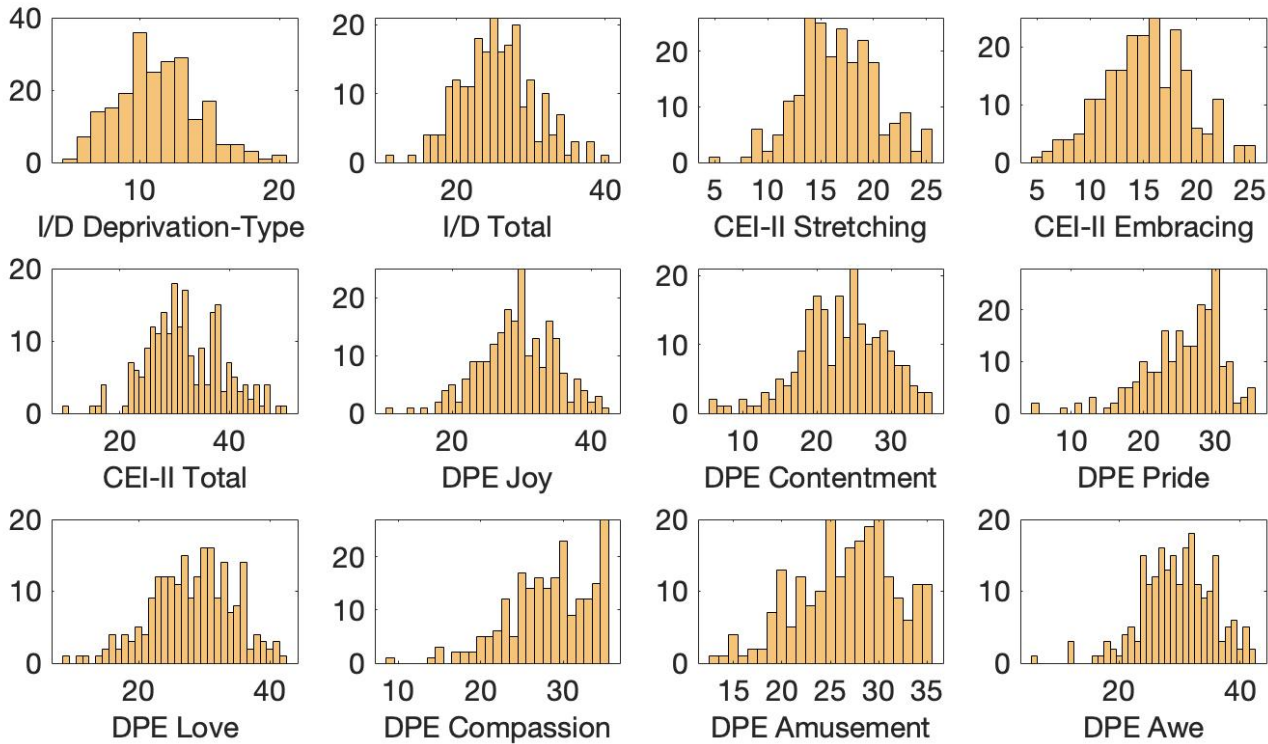

Figure S4 - Histograms demonstrating the distribution of personality traits in the current study. The $y$-axis is the frequency or the number of occurrences per each value on the $\mathrm{x}$-axis 

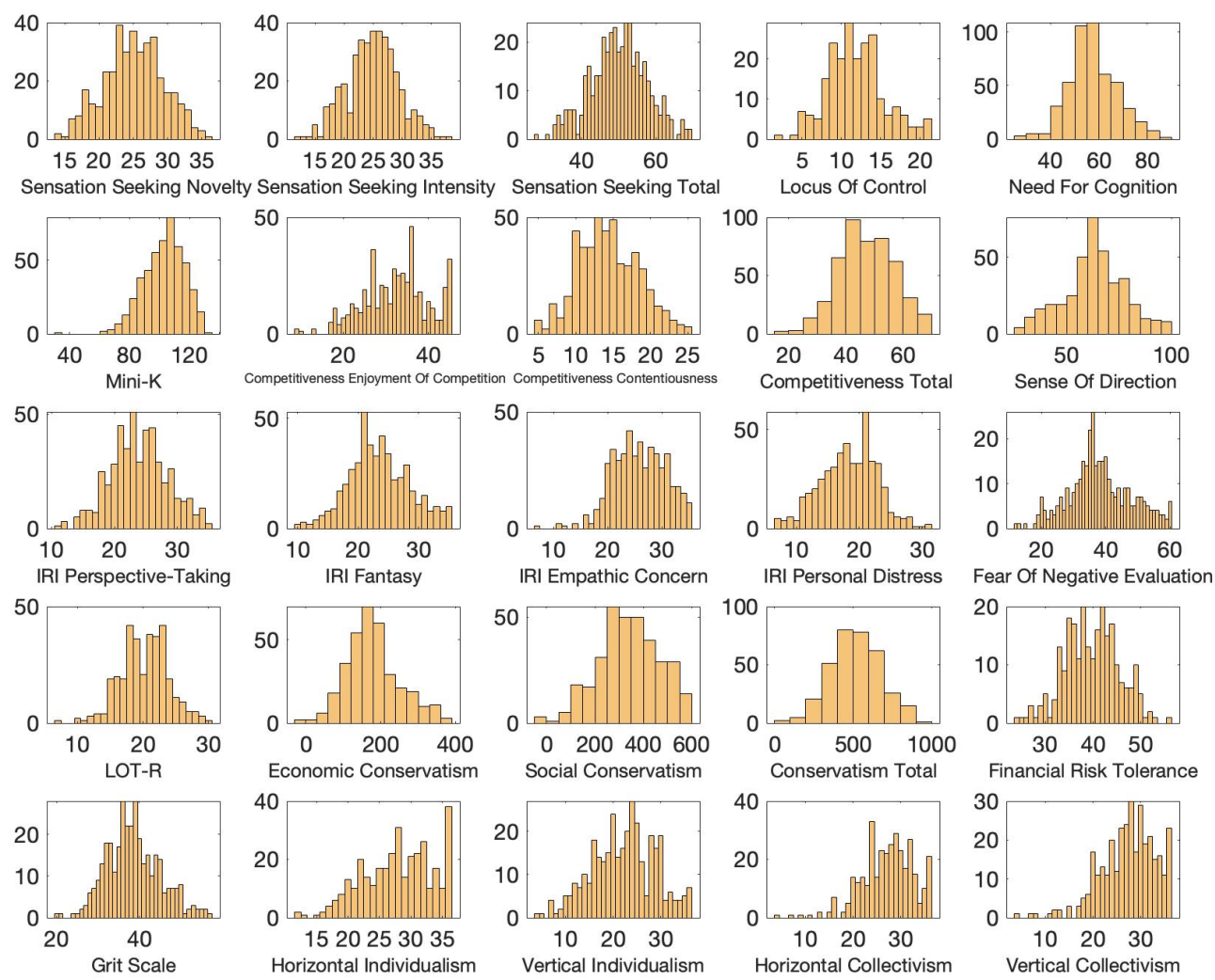

Figure S5 - Histograms demonstrating the distribution of personality traits in the current study. The $y$-axis is the frequency or the number of occurrences per each value on the $\mathrm{x}$-axis 


\section{Bonferroni-Holm Correction for Multiple Comparisons}

Table S1: Bonferroni-Holm's adjusted p's for top 20 correlations with time-of-semester trait $\quad \mathrm{r} \quad \mathrm{p} \quad$ adjusted $\mathrm{p}$

\begin{tabular}{|c|c|c|c|}
\hline Arnett Sensation Seeking Novelty & 0.28 & $2.68 \mathrm{E}-08$ & $2.82 \mathrm{E}-06$ \\
\hline Arnett Sensation Seeking total & 0.26 & $2.06 \mathrm{E}-07$ & $2.15 \mathrm{E}-05$ \\
\hline Grit Scale & -0.26 & $9.61 \mathrm{E}-07$ & $9.90 \mathrm{E}-05$ \\
\hline IRI Empathic concern & -0.17 & $1.80 \mathrm{E}-04$ & 0.0183 \\
\hline C4 Achievement Striving & -0.25 & 2.13E-04 & 0.0215 \\
\hline A4 Cooperation & -0.24 & 3.94E-04 & 0.0394 \\
\hline BIS-11 Attentional-Attention & 0.18 & 4.92E-04 & 0.0487 \\
\hline IRI Perspective-taking & -0.15 & $6.79 \mathrm{E}-04$ & 0.0665 \\
\hline Family Income & 0.15 & $1.07 \mathrm{E}-03$ & 0.1039 \\
\hline Arnett Sensation Seeking Intensity & 0.16 & $1.10 \mathrm{E}-03$ & 0.1059 \\
\hline Conscientiousness & -0.21 & $1.39 \mathrm{E}-03$ & 0.1317 \\
\hline BIS-11 Nonplanning-Self Control & 0.16 & $1.39 \mathrm{E}-03$ & 0.1317 \\
\hline C5 Self Discipline & -0.20 & $3.43 \mathrm{E}-03$ & 0.3192 \\
\hline SES & 0.13 & $4.21 \mathrm{E}-03$ & 0.3876 \\
\hline BIS nonplaning & 0.14 & 4.37E-03 & 0.3981 \\
\hline BIS total & 0.14 & 4.43E-03 & 0.3986 \\
\hline E2 Gregariousness & 0.19 & $5.13 \mathrm{E}-03$ & 0.4567 \\
\hline Horizontal Collectivism & -0.15 & $5.17 \mathrm{E}-03$ & 0.4567 \\
\hline Dispositional Positive Emotions- Compassion & -0.19 & $5.77 \mathrm{E}-03$ & 0.5023 \\
\hline US Born & 0.12 & $6.83 \mathrm{E}-03$ & 0.5871 \\
\hline
\end{tabular}




\section{ANOVA Table}

Table S2: Significant ANOVA results: week-of-semester

\begin{tabular}{|c|c|c|c|c|c|}
\hline & & $\operatorname{Pr}>F$ & F value & df-1 & $\mathrm{df}-2$ \\
\hline \multirow[t]{4}{*}{ Demographic } & Gender & 0.014 & 2.13 & 12 & 472 \\
\hline & GPA High school & 0.001 & 2.90 & 12 & 470 \\
\hline & Dad Education & 0.024 & 1.98 & 12 & 465 \\
\hline & Family Income & 0.017 & 2.09 & 12 & 472 \\
\hline \multirow[t]{5}{*}{ Big Five } & Conscientiousness & 0.050 & 1.77 & 12 & 470 \\
\hline & -C5 Self Discipline & 0.011 & 2.30 & 11 & 208 \\
\hline & -N2 Anger & 0.023 & 2.09 & 11 & 208 \\
\hline & -N6 Vulnerability & $<0.001$ & $3.75 *$ & 11 & 208 \\
\hline & -E5 Excitement Seeking & 0.007 & 2.44 & 11 & 208 \\
\hline \multirow[t]{5}{*}{ BIS } & & 0.041 & 1.84 & 12 & 380 \\
\hline & Attentional & 0.025 & 1.98 & 12 & 380 \\
\hline & Attentional-Attention & 0.001 & 2.79 & 12 & 380 \\
\hline & Motor-Motor & 0.015 & 2.12 & 12 & 380 \\
\hline & Nonplanning-Self Control & 0.029 & 1.94 & 12 & 380 \\
\hline \multirow[t]{3}{*}{ Arnett Sensation Seeking } & & $<0.001$ & $6.29 *$ & 12 & 378 \\
\hline & -Novelty & $<0.001$ & $7.42 *$ & 12 & 378 \\
\hline & -Intensity & 0.002 & 2.68 & 12 & 378 \\
\hline Locus of Control & & 0.016 & 2.20 & 11 & 207 \\
\hline IRI & Empathic Concern & 0.004 & 2.46 & 12 & 468 \\
\hline Grit Scale & & $<0.001$ & $6.81 *$ & 10 & 331 \\
\hline \multirow[t]{2}{*}{ Individualism/Collectivism } & Vertical Individualism & 0.005 & 2.59 & 10 & 326 \\
\hline & Horizontal Collectivism & 0.022 & 2.12 & 10 & 326 \\
\hline
\end{tabular}

* significant at $\operatorname{Pr}<0.001$ 


\section{E. Partial Correlations}

Table S3: Significant correlations at $\mathrm{p}<.05$ after controlling for Gender

\begin{tabular}{|c|c|c|c|c|c|c|}
\hline \multirow[b]{2}{*}{ trait } & & \multicolumn{2}{|c|}{ time-of-semester } & \multicolumn{2}{|c|}{ time-of-day } & \multirow[b]{2}{*}{$\mathrm{N}$} \\
\hline & & $\mathrm{r}$ & $\mathrm{p}$ & $\mathrm{r}$ & $\mathrm{p}$ & \\
\hline Age & & -0.12 & 0.011 & -0.16 & $<0.001$ & 485 \\
\hline US born & & 0.14 & 0.002 & -0.01 & 0.892 & 485 \\
\hline Years in US & & 0.13 & 0.005 & -0.03 & 0.581 & 485 \\
\hline Family Income & & 0.13 & 0.003 & 0.02 & 0.698 & 485 \\
\hline SES & & 0.12 & 0.009 & 0.02 & 0.739 & 485 \\
\hline \multirow[t]{10}{*}{ Big Five } & Extraversion & 0.13 & 0.004 & -0.03 & 0.459 & 483 \\
\hline & -E2 Gregariousness & 0.18 & 0.008 & -0.01 & 0.930 & 220 \\
\hline & Agreeableness & -0.14 & 0.003 & 0.05 & 0.315 & 483 \\
\hline & -A4 Cooperation & -0.20 & 0.003 & -0.09 & 0.165 & 220 \\
\hline & Conscientiousness & -0.21 & 0.002 & -0.07 & 0.200 & 220 \\
\hline & -C3 Dutifulness & -0.16 & 0.017 & -0.02 & 0.745 & 220 \\
\hline & -C4 Achievement Striving & -0.23 & 0.001 & -0.08 & 0.247 & 220 \\
\hline & -C5 Self Discipline & -0.20 & 0.003 & -0.09 & 0.183 & 220 \\
\hline & N2 Anger & 0.14 & 0.033 & 0.06 & 0.361 & 220 \\
\hline & O6 Liberalism & -0.14 & 0.039 & 0.03 & 0.701 & 220 \\
\hline \multirow[t]{5}{*}{ BIS-11 } & & 0.14 & 0.007 & 0.02 & 0.705 & 393 \\
\hline & Attentional & 0.11 & 0.031 & 0.05 & 0.367 & 393 \\
\hline & -Attention & 0.17 & 0.001 & 0.02 & 0.715 & 393 \\
\hline & Nonplaning & 0.15 & 0.003 & 0.00 & 0.932 & 393 \\
\hline & -Self-Control & 0.16 & 0.002 & -0.02 & 0.674 & 393 \\
\hline \multirow[t]{3}{*}{ Arnett Sensation Seeking } & & 0.26 & $<0.001$ & -0.02 & 0.658 & 391 \\
\hline & Novelty & 0.28 & $<0.001$ & -0.05 & 0.358 & 391 \\
\hline & Intensity & 0.17 & 0.001 & 0.01 & 0.874 & 391 \\
\hline \multirow[t]{3}{*}{ IRI } & Empathic Concern & -0.15 & 0.001 & 0.08 & 0.070 & 481 \\
\hline & Perspective Taking & -0.14 & 0.003 & 0.06 & 0.214 & 481 \\
\hline & Personal Distress & 0.12 & 0.010 & 0.02 & 0.623 & 481 \\
\hline LOT-R & & -0.11 & 0.038 & -0.04 & 0.474 & 342 \\
\hline Grit Scale & & -0.26 & $<0.001$ & -0.06 & 0.239 & 342 \\
\hline Horizontal Collectivism & & -0.15 & 0.008 & -0.01 & 0.866 & 337 \\
\hline
\end{tabular}

Bold: significant at $\mathrm{p}<=0.001$ 